Revista Geográfica Digital. IGUNNE. Facultad de Humanidades. UNNE. Año 12. No 23. Enero - Junio 2015. ISSN 1668-5180 Resistencia, Chaco

\title{
CAMBIOS EN LAS ACTIVIDADES AGROPECUARIAS Y FORESTALES DE LA PROVINCIA DEL CHACO (ARGENTINA) Y SUS EFECTOS SOBRE LA POBLACIÓN RURAL
}

\section{CHANGES IN AGRICULTURAL AND FOREST ACTIVITIES IN THE PROVINCE OF CHACO (ARGENTINA) AND ITS IMPACT ON THE RURAL POPULATION}

\author{
Dr. Dante Edin Cuadra \\ Mg. Fernando Ariel Bonfanti \\ Prof. Rosana Feliza Andrada \\ Favio Eliezer Golemba \\ Fabio Daniel Vera \\ Dpto. de Geografía. Facultad de Humanidades. \\ Universidad Nacional del Nordeste. \\ E-mail: dantecuadra@yahoo.com
}

\begin{abstract}
Resumen
La primera actividad económica del Territorio del Chaco fue la explotación forestal. Al iniciarse el siglo $\mathrm{XX}$ se instalaron fábricas para explotar el quebracho colorado y obtener extracto de tanino. Con el paso del tiempo se fueron agregando, en forma incipiente, la agricultura y la cría de animales. A este tramo, comprendido entre fines del siglo XIX y 1930 se lo reconoce como el "Ciclo Foresto-industrial". Entre 1930 y 1960 se desarrolló el "Ciclo Algodonero", que representó el primer avance de la frontera agrícola, impulsó el poblamiento de las áreas rurales y dio origen a numerosas cooperativas diseminadas en los pueblos del interior del Chaco, en tanto, la explotación forestal seguía siendo importante, aunque ya se iniciaba la declinación en la producción del tanino. Luego de la crisis del cultivo textil se ingresó al "Ciclo de la Diversificación económica", entre 1960 y 1985, con la introducción de otras especies tradicionalmente arraigadas en la región pampeana (girasol, sorgo, maíz y trigo) y, asimismo, se impulsó la actividad ganadera, con lo cual se inició un proceso de intensa emigración rural. Desde mediados de la década de 1980 hasta nuestros días, se han producido cambios significativos en los patrones de producción, con fuertes implicancias a nivel económico, demográfico y socioambiental. A este último período, se lo identifica como el "Ciclo Tecno-productivo", caracterizado por la creciente tecnificación de la agricultura, de la ganadería y de la industria forestal, una gran expansión de la soja, al tiempo que las áreas rurales continúan perdiendo población.
\end{abstract}

\section{Palabras claves}

Agricultura; Ganadería; Explotación forestal; Producción de tanino; Población rural.

\begin{abstract}
The first economic activity in the Chaco was the extraction of timber from native forests. At the beginning of the twentieth century, factories were established to obtain quebracho tannin extract. Over time, agriculture and livestock were added as incipient activities. This stage, since the late nineteenth century until 1930, is recognized as the "Industrial forest cycle". Between 1930 and 1960, the "Cotton cycle", which represented the first advance of the agricultural frontier was developed. This activity boosted the population of rural areas and led to numerous cooperatives scattered in villages inside the Chaco; meanwhile, logging was still important, but the decrease in tannin production had already begun. After the cotton crisis, between 1960 and 1985, the "Economic diversification cycle" began, with the introduction of other species traditionally rooted in Argentina's Pampas (sunflower, sorghum, maize and wheat) and an increased livestock activity, which triggered a process of intense migration of the rural population. Since the mid-1980s until today, there have been significant changes in production
\end{abstract}

Publicado en formato digital: Dr. Dante Edin Cuadra y otros. CAMBIOS EN LAS ACTIVIDADES AGROPECUARIAS Y FORESTALES DE LA PROVINCIA DEL CHACO (ARGENTINA) Y SUS EFECTOS SOBRE LA POBLACIÓN RURAL. Revista Geográfica Digital. IGUNNE. Facultad de Humanidades. UNNE. Año 12. No 23. Enero - Junio 2015. ISSN 1668-5180 Resistencia, Chaco.

En: http://hum.unne.edu.ar/revistas/geoweb/default.htm 
patterns, with strong implications at the economic, demographic and socio-environmental levels. The latter period is identified as the "Techno-productive cycle", characterized by increased mechanization of agriculture, livestock and forestry, and a large expansion of soybean, while rural areas continue to lose population.

\section{Keywords}

Agriculture; Livestock; Forestry; Tannin production; Rural population.

Publicado en formato digital: Dr. Dante Edin Cuadra y otros. CAMBIOS EN LAS ACTIVIDADES AGROPECUARIAS Y FORESTALES DE LA PROVINCIA DEL CHACO (ARGENTINA) Y SUS EFECTOS SOBRE LA POBLACIÓN RURAL. Revista Geográfica Digital. IGUNNE. Facultad de Humanidades. UNNE. Año 12. No 23. Enero - Junio 2015. ISSN 1668-5180 Resistencia, Chaco.

En: http://hum.unne.edu.ar/revistas/geoweb/default.htm 
Revista Geográfica Digital. IGUNNE. Facultad de Humanidades. UNNE. Año 12. No 23. Enero - Junio 2015. ISSN 1668-5180 Resistencia, Chaco

\section{Introducción}

El paisaje chaqueño se caracterizó históricamente por el dominio del bosque subtropical. La explotación de los recursos forestales a escala industrial se iniciaría en la primera década del siglo XX con el emplazamiento de las fábricas de tanino en el sur y este del Territorio Nacional del Chaco, en concomitancia con la corriente explotadora desatada precedentemente en el noreste santafesino. Estos establecimientos industriales, si bien se situaban en centros urbanos (o los generaban), tenían un amplio radio de acción sobre extensas áreas forestales, sobre todo de quebrachales explotables, de modo que la extracción de rollizos oficiaba de cuña de penetración para la implementación de vías de comunicación y de otras actividades económicas como la ganadería y la agricultura. De hecho, la empresa 'La Forestal` desarrollaba labores pecuarias muy importantes en sus latifundios. “...en 1914 la industria forestal proveía el 54\% de la producción del Chaco, habiendo atraído al Territorio una proporción similar de habitantes que dependían de ella". (Miranda, G., 2005: 186)

Entre 1930 y 1960, una parte importante de las tierras forestales fueron destinadas al cultivo del algodón, originándose un extendido paisaje agrícola-forestal, en tanto las tierras con escasa aptitud para los cultivos se utilizaron para desarrollar la ganadería bovina extensiva sobre pastizales, montes, sabanas y parques.

El pasaje del siglo XX al XXI ha encontrado al Chaco en pleno proceso de cambios en materia agroganadera y forestal. La crisis experimentada por el cultivo algodonero y por los sectores sociales involucrados (braceros, pequeños y medianos productores, industriales y transportistas, entre otros) durante el proceso de "pampeanización" de la llanura chaqueña que comenzó a vislumbrarse desde los años '60, se vio -en parte- aliviada en los años '90 con un repunte extraordinario del algodón, tras lo cual se produjo una estrepitosa caída de su superficie sembrada, en contraposición con el notable aumento del área sojera, el fortalecimiento de la ganadería bovina y una intensificación de la extracción de maderas provenientes de los bosques nativos. Estas transformaciones, reflejos de la creciente antropización impulsada por las demandas de los mercados externo e interno, han conformado distintos paisajes en el espacio chaqueño desde los años '90 en adelante. El mejoramiento internacional de los precios de algunos productos agrícolas, sobre todo de la soja, ha tenido un fuerte impacto sobre el sistema agro-productivo del Chaco. Esta oleaginosa pasó a ser predominante en gran parte de la provincia, aunque han permanecido áreas en las que el cultivo principal siguió siendo el algodón.

\section{Desarrollo}

La primera mitad del siglo XX ha sido una etapa de plena colonización y dinamismo demográfico, económico y social en el Chaco, con las limitaciones y problemáticas propias de un espacio periférico que pretendía ser integrado al 'país productivo' bajo la modalidad de Territorio Nacional. De esta manera, el espacio chaqueño se hallaba atravesado por políticas centralistas neoliberales impartidas desde el poder estatal situado en Buenos Aires (situación que se repetía en los demás Territorios Nacionales), contando con un representante designado por el Poder Ejecutivo Nacional, como era la figura del Gobernador Territorial, encargado de implementar dichas acciones en el terreno.

Este tramo de la historia chaqueña se caracterizó por el crecimiento de todos los indicadores analizados: extracción de maderas nativas, producción de tanino, superficie algodonera, cantidad de vacunos y población rural, es decir, que fue una etapa expansiva en términos sociodemográficos y económicos. La pirámide de población de 1914 se mostraba expandida en edades jóvenes debido a la incorporación de mano de obra extranjera y argentina, su base era ancha debido a la alta natalidad y su cúspide muy estrecha (pocos ancianos), pero hacia 1947 ya adquiría la forma triangular típica, reflejando un mayor equilibrio demográfico en cuanto a la distribución por edad y sexo. El Dr. Maeder, refiriéndose a la etapa territoriana del Chaco entre 1916 y 1945, escribió: "Fue un período de crecimiento rápido y por momentos desordenado, con aumento extraordinario de la población, ampliación de la frontera agrícola, éxito de los cultivos de algodón y crisis de la explotación de la industria forestal." (Maeder, E., 1997: 189).

Publicado en formato digital: Dr. Dante Edin Cuadra y otros. CAMBIOS EN LAS ACTIVIDADES AGROPECUARIAS Y FORESTALES DE LA PROVINCIA DEL CHACO (ARGENTINA) Y SUS EFECTOS SOBRE LA POBLACIÓN RURAL. Revista Geográfica Digital. IGUNNE. Facultad de Humanidades. UNNE. Año 12. No 23. Enero - Junio 2015. ISSN 1668-5180 Resistencia, Chaco.

En: http://hum.unne.edu.ar/revistas/geoweb/default.htm 
Revista Geográfica Digital. IGUNNE. Facultad de Humanidades. UNNE. Año 12. No 23. Enero - Junio 2015. ISSN 1668-5180 Resistencia, Chaco

Hacia 1950, casi la totalidad de la superficie dispuesta para la agricultura en el Chaco estaba orientada al cultivo del algodón (más de 400.000 hectáreas). Por entonces, el número de cabezas bovinas, que desde los años '30 superaba el millón, empezaba a evidenciar una transitoria declinación. Los volúmenes de maderas extraídas del bosque nativo se caracterizaban por las bruscas oscilaciones inter-pluri-anuales, producto de las variaciones de la demanda, de los precios, del stock acumulado en las fábricas y de las condiciones meteorológicas (asociadas a la transitabilidad de los caminos), que en promedio se aproximaban a unas 700.000 toneladas anuales, la mayor parte de ellas dirigidas a la producción de extracto de tanino (con volúmenes también irregulares, que se movían en torno a las 200.000 toneladas por año). En tanto, la población rural se encontraba en pleno crecimiento, sobrepasando los 300.000 habitantes a mediados del siglo XX.

La crisis algodonera se hizo sentir a fines de la década de 1950 cuando el Chaco ya se encontraba constituida como provincia, profundizándose en el decenio siguiente, cuando el área sembrada llegó a reducirse a la mitad. Sucesivos altibajos se prolongarían hasta mediados de 1980. Sin embargo, la superficie cultivada total -hasta fines de los años '70- mostró una tendencia creciente con la incorporación de otros cultivos llamados "pampeanos" como el maíz, el sorgo, el trigo y el girasol, excediendo las 800.000 hectáreas. Por entonces, la extracción de maderas mantenía e, incluso, aumentaba levemente sus registros, al tiempo que la industria taninera evidenciaba síntomas de crisis, reduciendo a la mitad su producción. Por el contrario, las existencias ganaderas se incrementaban y lograban llegar al millón y medio de cabezas bovinas.

La población rural solo pudo sostener su crecimiento hasta 1960 (en los años '50 ya mostraba una visible desaceleración), para luego invertir notoriamente esa tendencia y registrar -a fines de los '70un monto de 280.000 residentes (18\% menos que en 1960). La pirámide de población no lograba modificarse significativamente en 1960, aunque exhibía una reducción en la proporción de habitantes masculinos de 20 a 29 años en comparación con el año 1947. Para 1970, ya era notable el estrechamiento en edades jóvenes que mostraba la gráfica.

Entre la parte final de la década de 1970 y mediados de los ' 80 se visualiza una acentuada caída de algunos indicadores de actividad económica en el Chaco, al tiempo que otros se mostraban estancados, en concordancia con el período de facto que vivió el país (1976-1983) y el duro reinicio de la vida en democracia. "...la gestión económica del gobierno militar que asumió en 1976 estableció que la devaluación del tipo de cambio debía determinar la tasa de inflación interna", generando "...un retraso de la paridad cambiaria. El precio del algodón, como consecuencia de la sobrevaluación, se vio afectado debido a que dependía de la cotización del mercado internacional y del tipo de cambio nacional." (Manoiloff, R., 2001: 382) El año 1986 sería el momento más crítico, según la evidencia de la mayoría de las variables analizadas, una verdadera inflexión a partir dela cual la superficie y los volúmenes de producción agropecuaria y forestal volvieron a ascender notoriamente, aunque ello no benefició a la población rural, cuya curva continuó con una tendencia declinatoria. La población general lograba equilibrarse en 1980, pero en las décadas siguientes las pirámides demográficas irían reduciendo sus bases y ensanchando sus cimas, poniendo de manifiesto un proceso de incipiente envejecimiento demográfico.

Publicado en formato digital: Dr. Dante Edin Cuadra y otros. CAMBIOS EN LAS ACTIVIDADES AGROPECUARIAS Y FORESTALES DE LA PROVINCIA DEL CHACO (ARGENTINA) Y SUS EFECTOS SOBRE LA POBLACIÓN RURAL. Revista Geográfica Digital. IGUNNE. Facultad de Humanidades. UNNE. Año 12. No 23. Enero - Junio 2015. ISSN 1668-5180 Resistencia, Chaco.

En: http://hum.unne.edu.ar/revistas/geoweb/default.htm 
Revista Geográfica Digital. IGUNNE. Facultad de Humanidades. UNNE. Año 12. No 23. Enero - Junio 2015. ISSN 1668-5180 Resistencia, Chaco

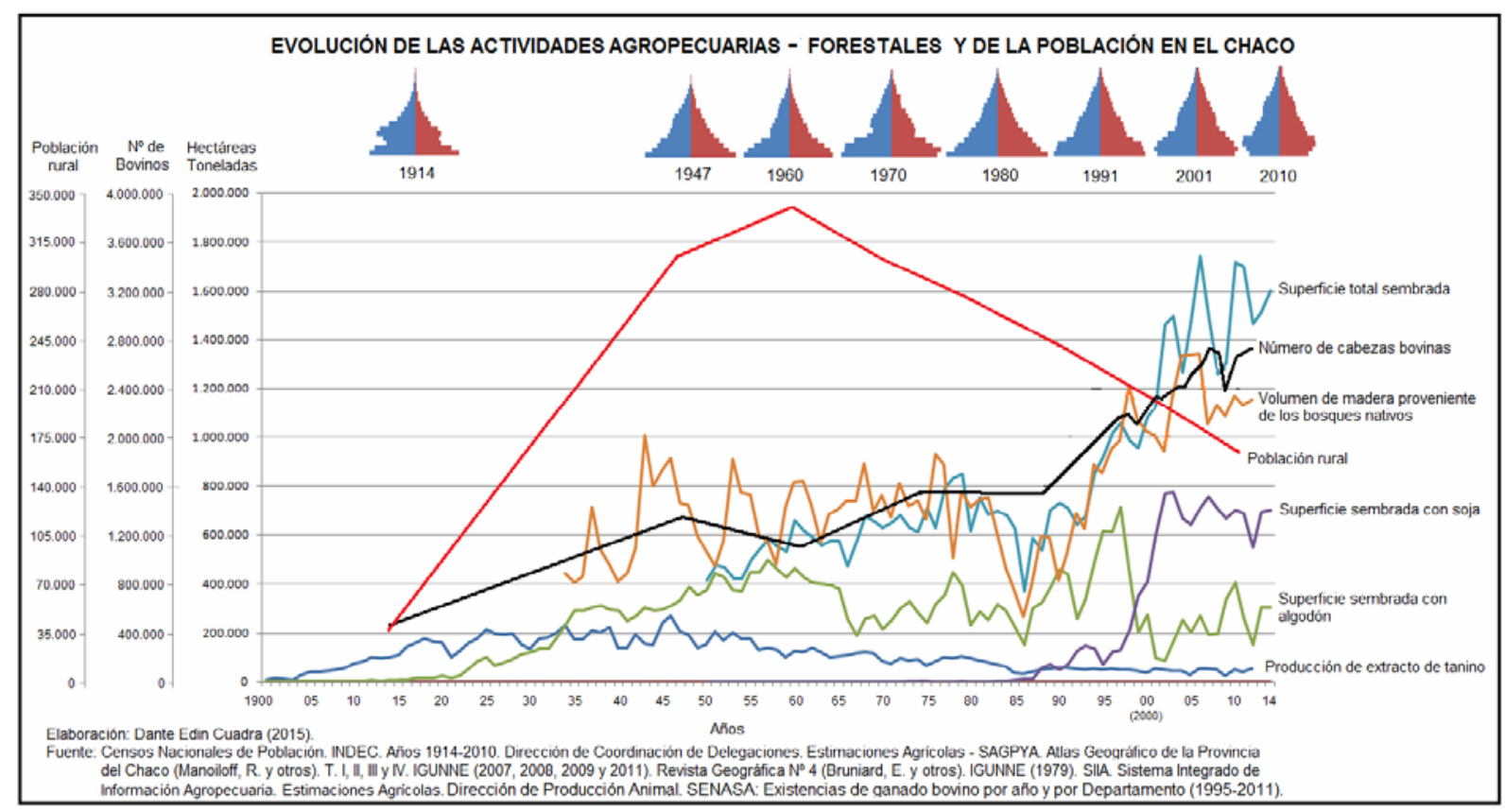

Figura $N^{\circ} 1$

Desde fines de los '80 a nuestros días, se observa un comportamiento muy diferente en las actividades económicas de la provincia: un repunte inicial de la superficie algodonera hasta superar valores históricos (más de 600.000 hectáreas sembradas) hacia mediados de los '90 y, luego, una nueva crisis que la lleva a oscilar casi siempre por debajo de las 300.000 hectáreas. Un comportamiento exactamente opuesto se advierte en esa etapa en la superficie destinada al cultivo de la soja, que pasó de ocupar unas 100.000 hectáreas en los años '90 a valores próximos a las 700.000 hectáreas en los decenios siguientes. Esta situación determinó un marcado aumento del área total destinada a la agricultura, que logró cuadruplicarse entre mediados de los ' 80 y el presente (con registros por arriba y por debajo de 1,6 millones de hectáreas).

La ganadería, que se mostró estabilizada a nivel de sus stocks durante buena parte de los años '70 y '80, iniciaría a fines de esta última década un notable crecimiento (por cierto, con algunos altibajos producidos por cuestiones de mercado y, fundamentalmente, por factores meteorológicos, tal el caso de las sequías, como ha sucedido en el año 2009, también con efectos sobre la agricultura). En términos absolutos, entre mediados de los ' 80 y 2008, se incrementaron en un millón de cabezas las existencias bovinas en los campos chaqueños.

La explotación de maderas nativas también registró un fuerte aumento, pasando de unas 300.000 toneladas obtenidas en 1986 a superar anualmente el millón de toneladas desde mediados de los años '90 en adelante (la producción taninera ha venido oscilando en torno a las 50.000 toneladas de extracto en este período, generadas en las fábricas que aún subsisten en las localidades de Puerto Tirol y La Escondida).

La población rural continuó su tendencia restrictiva, al pasar de un registro de 250.000 personas al promediar los ' 80 a poco más de 160.000 habitantes en 2010 , situación que evidencia claramente que los cambios operados en el territorio en materia de producción económica no contemplaron la retención de los habitantes rurales, desprendiéndose de un invalorable capital cultural -sobre todo agrícola- que se conformó durante varias décadas en el interior del Chaco.

En el gráfico que sigue, se han encerrado dentro del óvalo las curvas que manifiestan claramente el fenómeno socio-productivo operado en el Chaco en el período que se extiende desde 1985 hasta el

Publicado en formato digital: Dr. Dante Edin Cuadra y otros. CAMBIOS EN LAS ACTIVIDADES AGROPECUARIAS Y FORESTALES DE LA PROVINCIA DEL CHACO (ARGENTINA) Y SUS EFECTOS SOBRE LA POBLACIÓN RURAL. Revista Geográfica Digital. IGUNNE. Facultad de Humanidades. UNNE. Año 12. No 23. Enero - Junio 2015. ISSN 1668-5180 Resistencia, Chaco.

En: http://hum.unne.edu.ar/revistas/geoweb/default.htm 
Revista Geográfica Digital. IGUNNE. Facultad de Humanidades. UNNE. Año 12. No 23. Enero - Junio 2015. ISSN 1668-5180 Resistencia, Chaco

presente: el área sojera le arrebató el lugar de privilegio al algodón, creció en forma significativa la superficie total sembrada, el stock bovino y la explotación forestal (esta última con una leve disminución -no sostenida- a partir de la vigencia del Ordenamiento Territorial de los Bosques Nativos en la provincia). Es impactante el cruce perpendicular (en perceptible descenso) de la curva correspondiente a la población rural, respecto de las tres últimas variables mencionadas. La producción de tanino, fuera del campo destacado, aparece como una actividad estancada, cumpliendo la fase final de un modelo productivo perimido y sin horizontes en el siglo XXI.

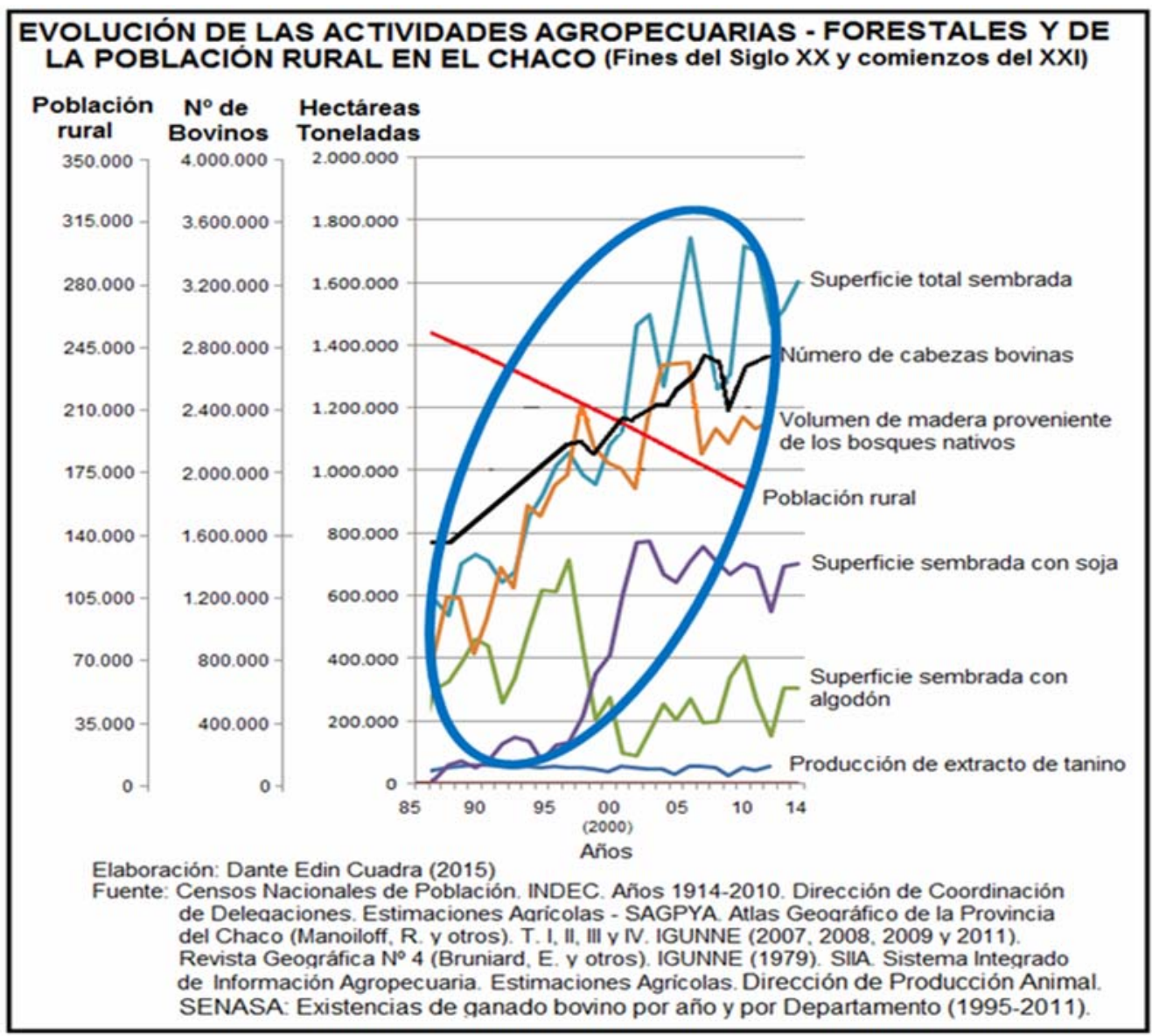

Figura $\mathrm{N}^{\circ} 2$

Como se observa en los gráficos precedentes, el Chaco se perfiló como una provincia algodonera y forestal hasta 1960, etapa en la que las colonias agrícolas crecían demográficamente y la ganadería pasaba por momentos de crecimiento (hasta fines de la década del '40) y de retroceso (desde entonces hasta los inicios de los '60) ante el ímpetu tomado por el monocultivo. Durante los años '60 y'70 la frontera agropecuaria se fue expandiendo con la incorporación de otros cultivos y de animales vacunos, que ocupaban las tierras deforestadas e, incluso, áreas que habían sido algodoneras en la etapa anterior. "La brusca caída del área sembrada con algodón entre 1957-1958 y 1967-1968, la presencia de otros cultivos (extraregionales) que comenzaron a eclipsar el reinado del textil y el comienzo de la emigración rural...son hechos más que evidentes de que una nueva situación productiva en el agro se estaba gestando en el Chaco." (Manoiloff, R., 2001:357)

Publicado en formato digital: Dr. Dante Edin Cuadra y otros. CAMBIOS EN LAS ACTIVIDADES AGROPECUARIAS Y FORESTALES DE LA PROVINCIA DEL CHACO (ARGENTINA) Y SUS EFECTOS SOBRE LA POBLACIÓN RURAL. Revista Geográfica Digital. IGUNNE. Facultad de Humanidades. UNNE. Año 12. No 23. Enero - Junio 2015. ISSN 1668-5180 Resistencia, Chaco.

En: http://hum.unne.edu.ar/revistas/geoweb/default.htm 
Revista Geográfica Digital. IGUNNE. Facultad de Humanidades. UNNE. Año 12. No 23. Enero - Junio 2015. ISSN 1668-5180 Resistencia, Chaco

El tramo que transitamos, desde mediados de los ' 80 hasta la actualidad, se ha caracterizado por el aumento de la superficie total sembrada (con dominancia de la soja sobre el algodón desde el final de los '90 en adelante), pero además, por el incremento -en líneas generales- de las existencias bovinas y un gran impulso de la explotación forestal. Estas actividades, a diferencia del cultivo del algodón (que en la etapa 1930-1960 se realizaba en chacras pequeñas y con escasa mecanización), se caracterizan por captar muy poca mano de obra y desarrollarse en superficies de amplias extensiones. El cultivo de soja, igual que el girasol, trigo, sorgo y maíz, en gran parte del Chaco (sobre todo en el centro y sudoeste) se realiza en forma mecanizada, utilizándose de manera creciente los implementos tecnológicos disponibles en materia de producción agrícola. La ganadería y la explotación del bosque tienen una demanda de empleo muy acotada y, parte de ella, de carácter transitorio. La industria forestal se radica preferentemente en el medio urbano, donde la mano de obra, la disponibilidad energética y de otros servicios, como las alternativas de comercialización, la capacitación y la conectividad están garantizadas. La producción de tanino viene declinando desde los años '50, sin posibilidades de revertir la tendencia ante la disminución de las existencias de quebracho colorado.

\section{La dinámica agrícola}

Entre la década de 1960 y mediados de los '80, a pesar de la crisis algodonera desatada, el cultivo textil siguió siendo predominante en cuanto a superficie sembrada en la mayoría de las campañas agrícolas a nivel provincial y rara vez era superado por el girasol o el sorgo. No obstante, este período se distinguió porque el algodón -que había sido un monocultivo hasta 1960- pasó a ser una de las opciones cultivables, donde la sumatoria de las superficies dedicadas al girasol, sorgo, trigo y maíz superaba a la del algodón. "...entre los años 1960 y 1970, la caída de la superficie sembrada con algodón dejó disponibles tierras aptas, con vocación agrícola probada, lo que posibilitó una aceleración de la penetración de los cultivos pampeanos en el ámbito subtropical." (Bruniard, E., 1979: 106-107)

A partir de la segunda mitad de la década de 1980, hasta finales de la siguiente, la superficie algodonera tuvo un repunte extraordinario (superando todos sus registros históricos, con más de 700.000 hectáreas), en tanto los otros cultivos restringieron su cobertura, con excepción de la soja que empezaba a extenderse notablemente.

En la actualidad, el algodón tiene una producción oscilante y diferenciada espacialmente: en la mayor parte del territorio chaqueño este cultivo ha pasado a un segundo plano ante el avance sojero y sólo unos pocos departamentos lo tienen como cultivo principal (tomando en cuenta la superficie sembrada). A modo de ejemplo, en la campaña agrícola 2013/14, las jurisdicciones que tuvieron al algodón como cultivo predominante fueron Libertador General San Martín, Fray Justo Santa María de Oro, Mayor Luis Fontana, Quitilipi y Presidencia de la Plaza, en tanto San Lorenzo y O`Higgins igualaban la superficie sembrada con algodón y soja. En varios de estos departamentos, el grueso de las cosechas se realiza con maquinarias, dejando como consecuencia una fuerte y sistemática pérdida demográfica en el medio rural.

Entre 1985 y 2014 la superficie agrícola de la provincia del Chaco se incrementó en un 164\%. El gran salto se produjo al promediar la década de 1990. Desde 2007 a la actualidad, la superficie cultivada oscila por arriba y por debajo del millón y medio de hectáreas sembradas en el Chaco.

En la campaña 1985-86 eran catorce los departamentos en los que el cultivo predominante era el algodón $(58,3 \%)$, en ocho lograba imponerse el girasol $(33,3 \%)$, en uno el sorgo $(4,2 \%)$ y, en el restante, el arroz (4,2\%). La soja no predominaba en ningún departamento por entonces. La mayor presencia del algodón a nivel de los departamentos, no implicaba que fuera el cultivo con mayor superficie sembrada en la provincia, ya que el girasol lo superaba (260.000 hectáreas, contra 221.000 del algodón).

En los departamentos ubicados en el centro-este (tradicionalmente algodoneros) y norte de la provincia el algodón era el cultivo con mayor superficie de siembra, a diferencia del sudoeste y centronoroeste, donde la preferencia la tenía el girasol. El departamento Almirante Brown en el oeste y

Publicado en formato digital: Dr. Dante Edin Cuadra y otros. CAMBIOS EN LAS ACTIVIDADES AGROPECUARIAS Y FORESTALES DE LA PROVINCIA DEL CHACO (ARGENTINA) Y SUS EFECTOS SOBRE LA POBLACIÓN RURAL. Revista Geográfica Digital. IGUNNE. Facultad de Humanidades. UNNE. Año 12. No 23. Enero - Junio 2015. ISSN 1668-5180 Resistencia, Chaco.

En: http://hum.unne.edu.ar/revistas/geoweb/default.htm 
Bermejo en el noreste, se inclinaban por el sorgo y el arroz, respectivamente (las condiciones ecológicas de ambas áreas extremas son muy diferentes: el sorgo resiste mejor que otros cultivos la restricciones hídricas propias del occidente árido, a la vez que el arroz exige abundancia de agua, situación propia del oriente chaqueño: allí, la presencia del río Paraguay hace posible el manejo del agua para el riego y el drenaje necesarios durante gran parte del ciclo de este cultivo).

\section{Figura $N^{\circ} 3$}

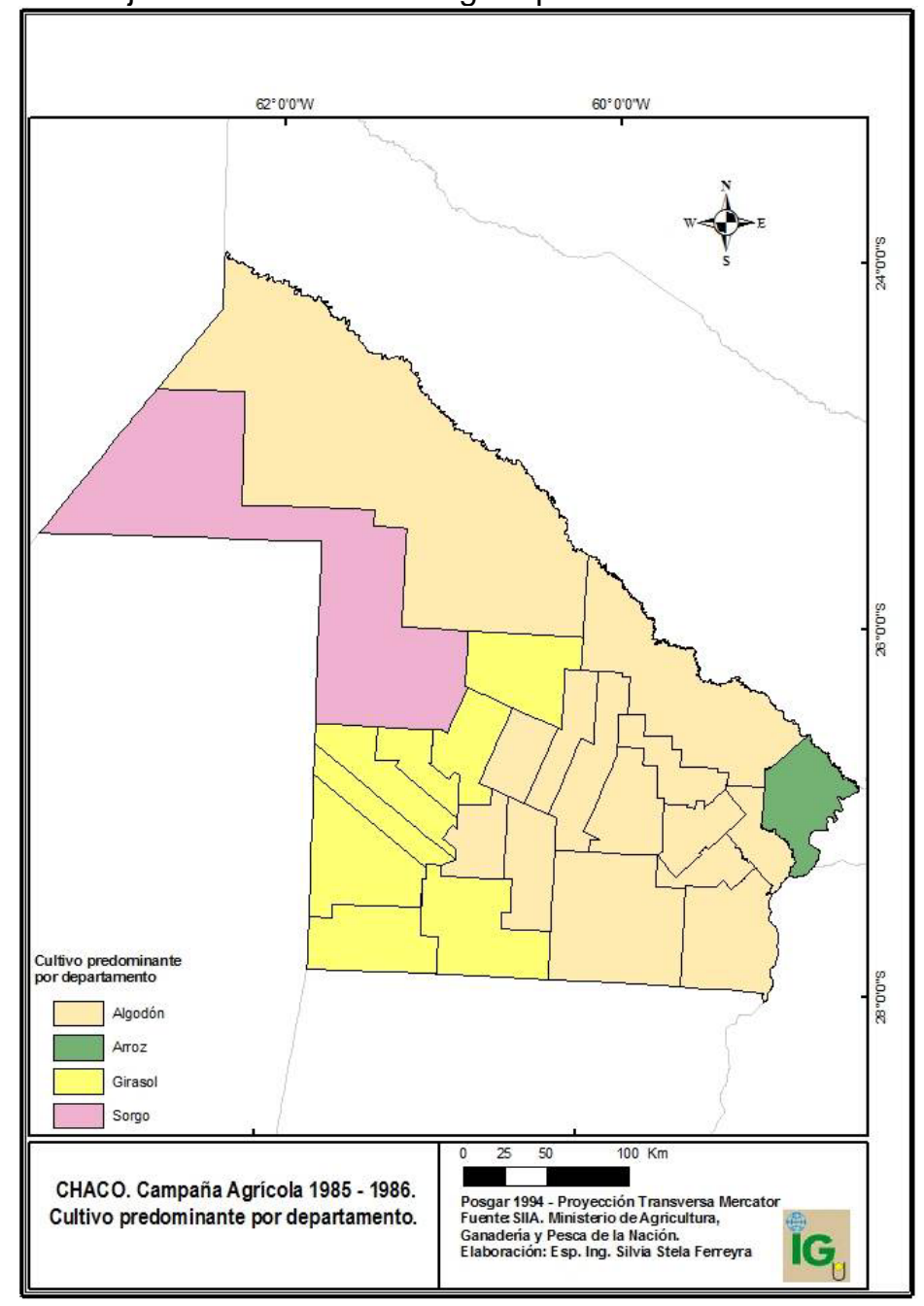

De la totalidad de la superficie agrícola del Chaco al promediar la década de 1980 (621.090 hectáreas), se evidencia que la mayor parte se hallaba concentrada en departamentos del sudoeste (12 de Octubre, Mayor Luis Fontana y Chacabuco), centro (Comandante Fernández y Maipú) y noreste (Libertador General San Martín), cada uno de los cuales reunía más del 6\% de las tierras de sembradío y, en conjunto, representaban más de la mitad del área cultivable de la provincia (56\%).

Otros departamentos del sudoeste (Fray Justo Santa María de Oro, 9 de Julio, General Belgrano, O`Higgins y San Lorenzo), del centro (Independencia y Quitilipi) y del noroeste (General Güemes) contenían entre 3 y $6 \%$ del área sembrada provincial, sumando entre todos algo más de 1/3 de la misma (35\%).

Publicado en formato digital: Dr. Dante Edin Cuadra y otros. CAMBIOS EN LAS ACTIVIDADES AGROPECUARIAS Y FORESTALES DE LA PROVINCIA DEL CHACO (ARGENTINA) Y SUS EFECTOS SOBRE LA POBLACIÓN RURAL. Revista Geográfica Digital. IGUNNE. Facultad de Humanidades. UNNE. Año 12. № 23. Enero - Junio 2015. ISSN 1668-5180 Resistencia, Chaco.

En: http://hum.unne.edu.ar/revistas/geoweb/default.htm 
El 9\% restante del área agrícola del Chaco se distribuía en diez departamentos, nueve de ellos situados en el centro-este (Bermejo, $1^{\circ}$ de Mayo, Libertad, San Fernando, Sargento Cabral, General Dónovan, Tapenagá, Presidencia de la Plaza y 25 de Mayo) y uno en el oeste (Almirante Brown). Ello refleja que en la porción oriental de la provincia, otrora algodonera minifundista, la agricultura pasó a tener un papel irrelevante, cediendo espacio a la ganadería como actividad principal y explotando los bosques ya empobrecidos que todavía brindaban usufructos, sobre todo para la producción de leña.

\section{Figura $N^{\circ} 4$}

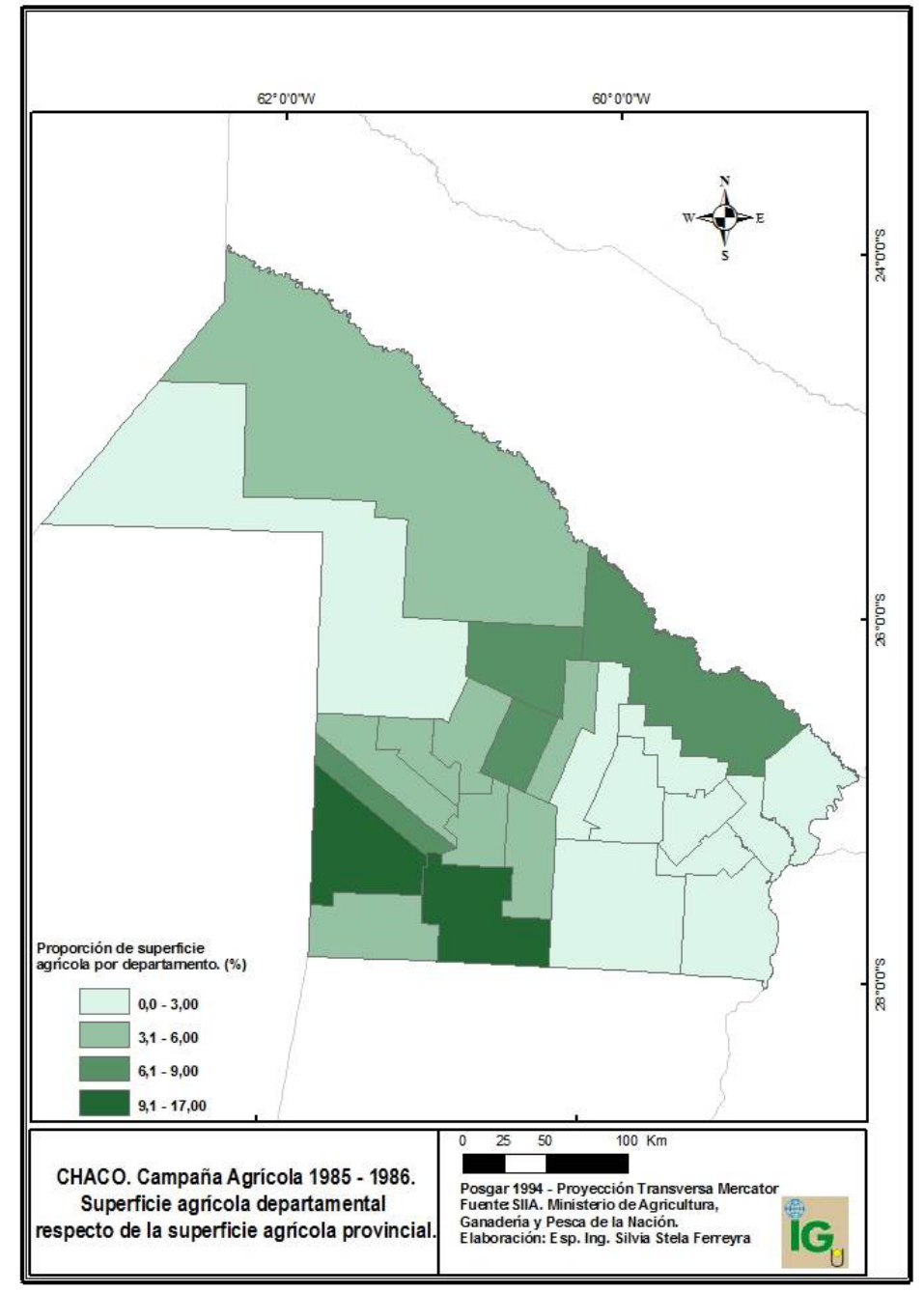

Con posterioridad a la campaña agrícola 1985/86, hasta el año 1998, el cultivo textil recuperó el liderazgo con bastante margen sobre los demás. La soja, desde fines de la década de 1980 venía mostrando una tendencia creciente, llegando incluso a posicionarse como segundo cultivo en algunas campañas de los años '90. Por entonces, la generalidad de los departamentos del Chaco destinaba mayor superficie al cultivo textil, como puede verse en la Figura № 5 (Campaña agrícola 1995/96). Las excepciones eran San Fernando en el sudeste y 2 de Abril en el sudoeste provincial, donde el cultivo más difundido era el maíz, en tanto Tapenagá no tenía registros de actividad agrícola.

El resurgimiento del cultivo que marcó una etapa épica en la sociedad chaqueña en décadas anteriores, alentó firmes esperanzas en los productores e industriales del sector algodonero en los

Publicado en formato digital: Dr. Dante Edin Cuadra y otros. CAMBIOS EN LAS ACTIVIDADES AGROPECUARIAS Y FORESTALES DE LA PROVINCIA DEL CHACO (ARGENTINA) Y SUS EFECTOS SOBRE LA POBLACIÓN RURAL. Revista Geográfica Digital. IGUNNE. Facultad de Humanidades. UNNE. Año 12. No 23. Enero - Junio 2015. ISSN 1668-5180 Resistencia, Chaco.

En: http://hum.unne.edu.ar/revistas/geoweb/default.htm 
años '90; muchas cooperativas que se encontraban paralizadas volvieron a reactivar sus maquinarias y producir fibras para la demanda nacional (varias de ellas fueron concesionadas a inversores privados), sin imaginar que muy pronto se experimentaría una nueva depresión, esta vez generada por la incidencia de factores externos. En los años '90 "Varios han sido los factores que determinaron la ampliación del área algodonera, particularmente en... el Sudoeste chaqueño, entre ellos podemos mencionar por ejemplo al aumento de las precipitaciones (corrimiento de la isohieta de 800 milímetros) las cuales permitieron sembrar en áreas que antes solo se podían lograr bajo riego; la reducción de los precios de los productos químicos, la implementación de tecnología y dentro de ella la mecanización de la cosecha". (Pertile, V., 2004:3)

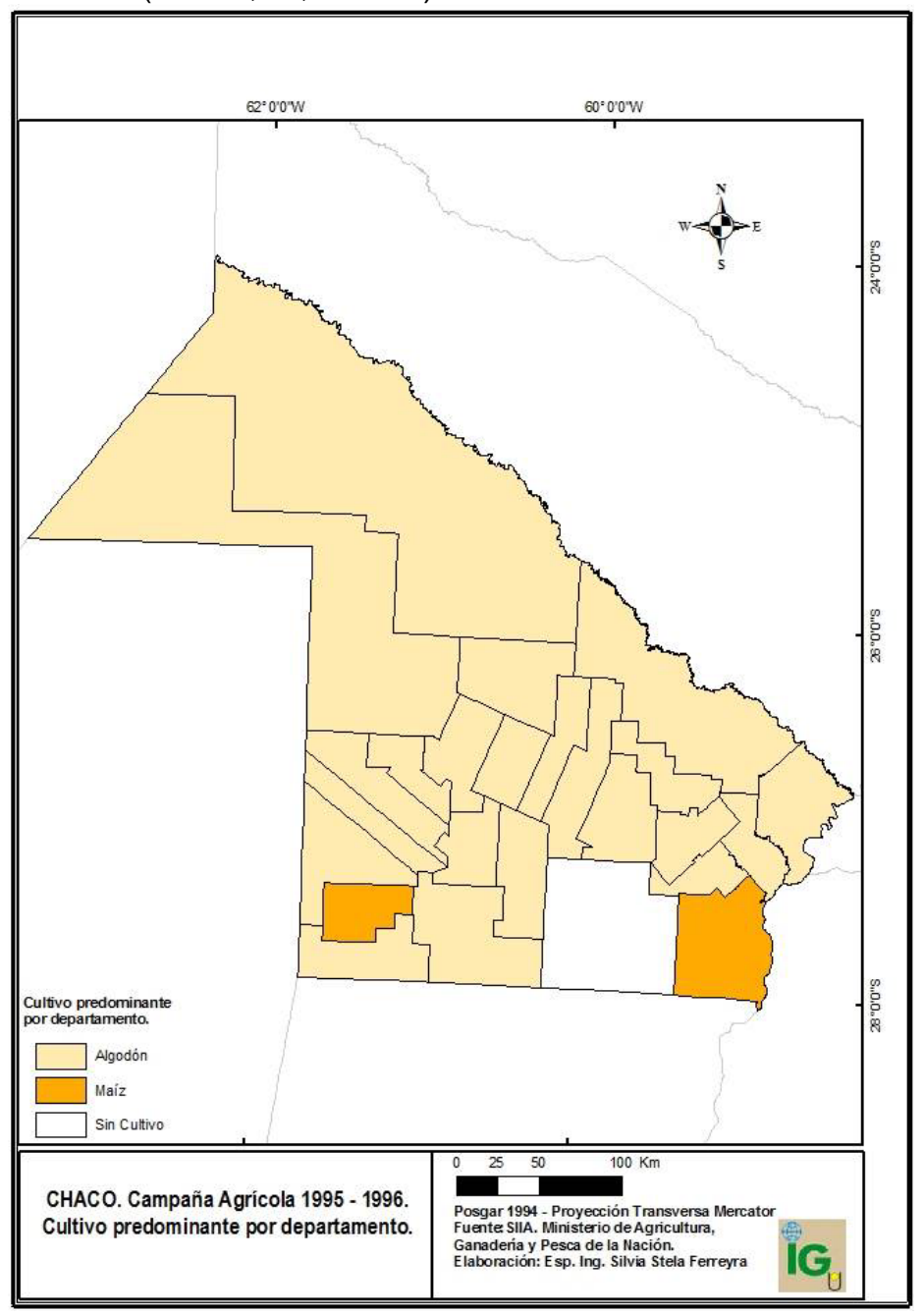

Figura $N^{\circ} 5$

La superficie sembrada en la campaña 1995/96 en el Chaco fue de 912.900 hectáreas, es decir, 47\% más que en 1985/86. La mitad oriental de la provincia, más volcada a la ganadería vacuna, se caracterizaba por su escasa participación en materia de cultivos, a excepción de los departamentos Libertador General San Martín y Presidencia de la Plaza, que se destacaban en la producción algodonera: esa extensa porción territorial contenía solamente el $21 \%$ del área de siembra de la provincia. Contrariamente, en el centro-sudoeste se emplazaba la mayor actividad agrícola

Publicado en formato digital: Dr. Dante Edin Cuadra y otros. CAMBIOS EN LAS ACTIVIDADES AGROPECUARIAS Y FORESTALES DE LA PROVINCIA DEL CHACO (ARGENTINA) Y SUS EFECTOS SOBRE LA POBLACIÓN RURAL. Revista Geográfica Digital. IGUNNE. Facultad de Humanidades. UNNE. Año 12. No 23. Enero - Junio 2015. ISSN 1668-5180 Resistencia, Chaco.

En: http://hum.unne.edu.ar/revistas/geoweb/default.htm 
(departamentos Comandante Fernández, 12 de Octubre, Chacabuco, O`Higgins y Mayor Luis Fontana: cada una de estas jurisdicciones contenía más del 6\% del área total sembrada del Chaco y, en conjunto, representaban el $43 \%$ del total provincial).

En la mitad occidental del territorio chaqueño, se observaban varios departamentos del centro-oeste, sudoeste y noroeste, que sostenían -cada uno de ellos- entre 3 y $6 \%$ del área sembrada de la provincia (9 de Julio, General Belgrano, Fray Justo Santa María de Oro, Independencia, Maipú, Almirante Brown y General Güemes), que en conjunto sumaban el 35\%. Solamente 2 de Abril, en el sudoeste, se mostraba con escasa relevancia agrícola.

Se evidencia, entre mediados de las décadas de 1980 y 1990, un afianzamiento de la actividad agrícola en el área centro y sudoeste del Chaco, como se desprende del incremento mostrado en la superficie de cultivos de los siguientes departamentos: O`Higgins (161\%), General Belgrano (111\%), 9 de Julio (99\%), Independencia (66\%) y Chacabuco (64\%). Ha sido notable el crecimiento de la cobertura de siembra en el departamento Almirante Brown, situado en el noroeste provincial, donde se produjo un aumento del 189\% en sólo 10 años. La propagación de la agricultura en estas áreas está relacionada directamente con el avance de la deforestación. (Insaurralde, J., 2014; Cuadra, D., 2012)

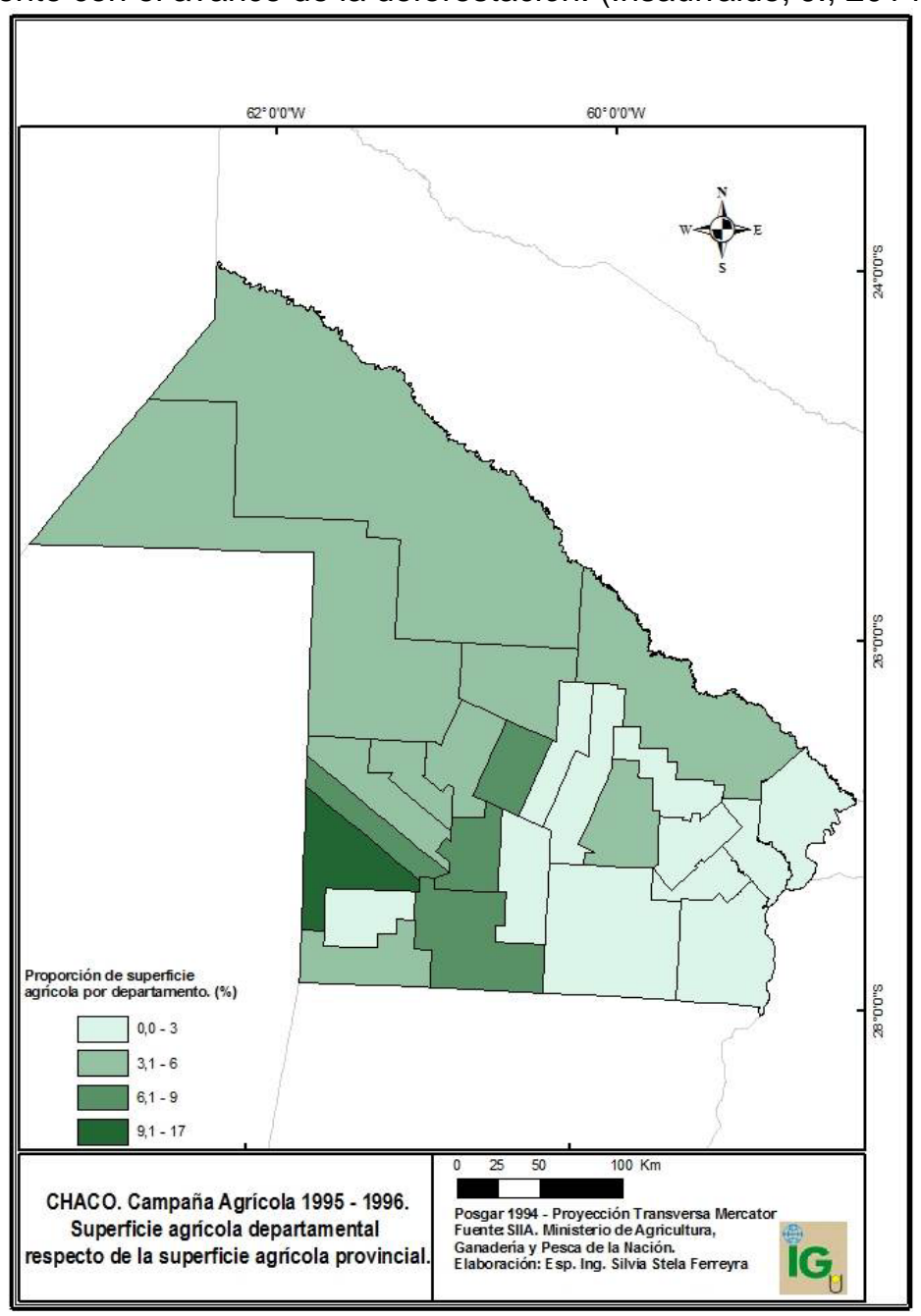

Figura $N^{\circ} 6$

Publicado en formato digital: Dr. Dante Edin Cuadra y otros. CAMBIOS EN LAS ACTIVIDADES AGROPECUARIAS Y FORESTALES DE LA PROVINCIA DEL CHACO (ARGENTINA) Y SUS EFECTOS SOBRE LA POBLACIÓN RURAL. Revista Geográfica Digital. IGUNNE. Facultad de Humanidades. UNNE. Año 12. No 23. Enero - Junio 2015. ISSN 1668-5180 Resistencia, Chaco.

En: http://hum.unne.edu.ar/revistas/geoweb/default.htm 
Tras la nueva crisis algodonera, la soja adquirió un impulso sin precedentes a partir de la campaña 1997/98, posicionándose en el primer lugar desde el año 1999 a la fecha en la provincia, en tanto el segundo lugar lo alternan el girasol y el algodón.

La superficie agrícola del Chaco hacia la segunda mitad de la década de 1980 nunca llegó a las 700.000 hectáreas, aún en las campañas más favorables, pero a fines de los '90 ya pudo superar el millón de hectáreas. Este proceso continúa en lo que va del siglo XXI, con campañas en las que se ha logrado sobrepasar la cifra de 1,7 millones de hectáreas, como ha ocurrido en 2006/07 y 2010/11. Ello indica que, en las últimas dos décadas, la superficie agrícola del Chaco se ha expandido un $70 \%$.

El área con neta predominancia sojera ha logrado emplazarse con continuidad en el centro, sudoeste, oeste y noroeste del Chaco, tal como lo muestra la Figura No 7 (Campaña agrícola 2013/14), donde diez departamentos lo tienen como cultivo hegemónico (incluido Sargento Cabral, como área disjunta en el noreste provincial), en tanto, otros dos (O 'Higgins y San Lorenzo) reparten superficies similares para la soja y el algodón. El área algodonera constituye una especie de media luna que une el extremo sudoeste con el centro, extendiéndose a los departamentos del norte (General Güemes y Libertador General San Martín), a los que se agrega Presidencia de la Plaza en el centro-este de la provincia. Las demás jurisdicciones orientales tienen escasa superficie destinada a la agricultura o directamente no la desarrollan (por ejemplo: Tapenagá y Libertad) y el cultivo dominante es variable entre los departamentos (maíz en 25 de Mayo, sorgo en General Dónovan, maíz y sorgo en $1^{\circ}$ de Mayo, girasol en San Fernando y arroz en Bermejo).

Publicado en formato digital: Dr. Dante Edin Cuadra y otros. CAMBIOS EN LAS ACTIVIDADES AGROPECUARIAS Y FORESTALES DE LA PROVINCIA DEL CHACO (ARGENTINA) Y SUS EFECTOS SOBRE LA POBLACIÓN RURAL. Revista Geográfica Digital. IGUNNE. Facultad de Humanidades. UNNE. Año 12. No 23. Enero - Junio 2015. ISSN 1668-5180 Resistencia, Chaco.

En: http://hum.unne.edu.ar/revistas/geoweb/default.htm 
Revista Geográfica Digital. IGUNNE. Facultad de Humanidades. UNNE. Año 12. No 23. Enero - Junio 2015. ISSN 1668-5180 Resistencia, Chaco

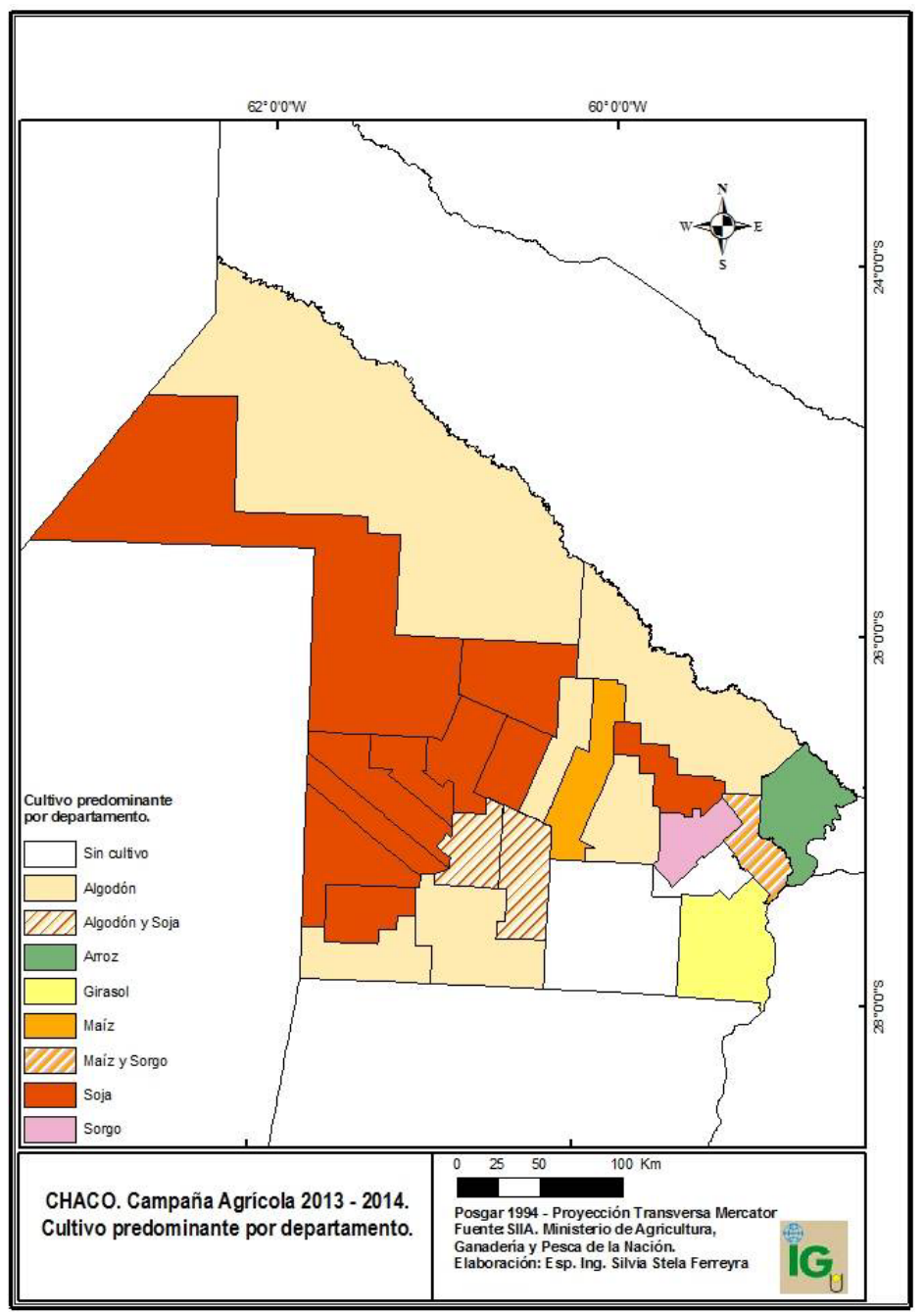

Figura $\mathrm{N}^{\circ} 7$

La campaña 1998-99 marcó el fin de la supremacía algodonera en la provincia. Por lo general, dependiendo de los precios y de las condiciones meteorológicas (muy variables espacial e interanualmente en el Chaco), los productores en cada campaña se ven condicionados a sembrar uno u otro cultivo, de modo que si las condiciones no han sido favorables para la siembra de algodón en noviembre-diciembre, posiblemente lo intenten con el girasol en julio-agosto, de manera que puede darse una relación inversa entre ambos cultivos. Otras veces, la sucesión puede ser trigo/girasol, trigo/maíz, trigo/sorgo, algodón/soja o soja/girasol. El maíz y el sorgo suelen seguirles -en superficie sembrada- a la soja, al algodón y al girasol: el volumen de siembra de los dos cereales nombrados se presenta más estable, con tendencia creciente en los últimos años, situación que refleja el aumento de su demanda por parte del sector ganadero. El trigo se muestra muy oscilante a través del tiempo y tiende a acompañar el comportamiento del girasol, más que del algodón. Cuando las condiciones de precios y de tiempo atmosférico son óptimas, suele ser una alternativa previa (de cosecha invernal) en suelos que luego se destinan a otros cultivos. El arroz se halla poco difundido en la provincia (sólo en dos o tres departamentos del noreste y, en algunas campañas, sólo en Bermejo), aunque aumentó su superficie sembrada a partir de la campaña 2007/08.

Publicado en formato digital: Dr. Dante Edin Cuadra y otros. CAMBIOS EN LAS ACTIVIDADES AGROPECUARIAS Y FORESTALES DE LA PROVINCIA DEL CHACO (ARGENTINA) Y SUS EFECTOS SOBRE LA POBLACIÓN RURAL. Revista Geográfica Digital. IGUNNE. Facultad de Humanidades. UNNE. Año 12. No 23. Enero - Junio 2015. ISSN 1668-5180 Resistencia, Chaco.

En: http://hum.unne.edu.ar/revistas/geoweb/default.htm 
Revista Geográfica Digital. IGUNNE. Facultad de Humanidades. UNNE. Año 12. No 23.

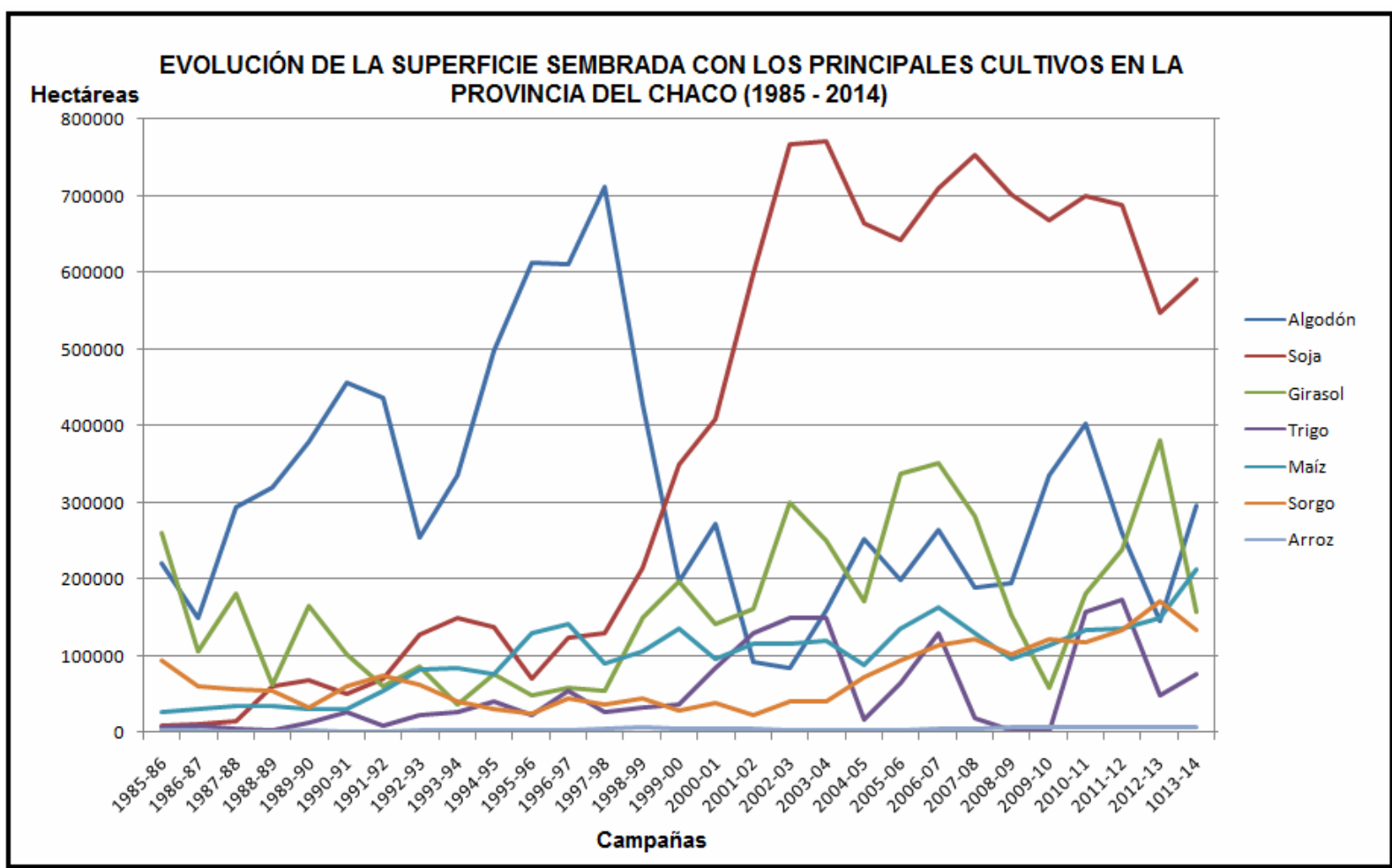

Elaboración: Dante Edin Cuadra.

Fuente: Sistema Integrado de Información Agropecuaria (SIIA). Programa de Servicios Agrícolas Provinciales. Ministerio de Agricultura, Ganaderia y Pesca de la Nación. 2015.

\section{Figura $\mathbf{N}^{\circ} 8$}

Las figuras $N^{\circ} 7$ y 9 muestran claramente que el área de mayor relevancia agrícola del Chaco se localiza en el centro-oeste, donde el cultivo predominante es la soja. Justamente, el departamento con mayor superficie de siembra es Almirante Brown, en el noroeste, con más de 250.000 hectáreas (17\% del total provincial), el cual ha aumentado su área de cultivo en un 557\% entre las campañas 1995/96 y $2013 / 14$, lo que equivale a un ritmo de $36,5 \%$ anual. Otros departamentos que han expandido sus tierras cultivables en ese mismo período, han sido: 2 de Abril (618\%), Independencia (109\%), 9 de Julio (102\%), General Belgrano (98\%), Fray Justo Santa María de Oro (74\%), Maipú (67\%), Mayor Luis Fontana (60\%), O’Higgins (48\%), Chacabuco (46\%), 12 de Octubre (40\%) y Comandante Fernández (14\%), todos en el centro-sudoeste de la provincia. Los departamentos nombrados representan el $71 \%$ del área total de siembra de la provincia.

El resto del Chaco, constituido por la mitad oriental de su territorio y el departamento General Güemes (ubicado en el noroeste), posee el remanente del 29\% de las tierras dedicadas al cultivo (cada división administrativa no llega a albergar el $3 \%$ respecto del total de hectáreas sembradas en la provincia) y corresponde a espacios en los que fue imponiéndose la cría de ganado extensivo y, en los últimos años, la instalación de establecimientos de modalidad intensiva (feedlots).

Publicado en formato digital: Dr. Dante Edin Cuadra y otros. CAMBIOS EN LAS ACTIVIDADES AGROPECUARIAS Y FORESTALES DE LA PROVINCIA DEL CHACO (ARGENTINA) Y SUS EFECTOS SOBRE LA POBLACIÓN RURAL. Revista Geográfica Digital. IGUNNE. Facultad de Humanidades. UNNE. Año 12. No 23. Enero - Junio 2015. ISSN 1668-5180 Resistencia, Chaco.

En: http://hum.unne.edu.ar/revistas/geoweb/default.htm 
Revista Geográfica Digital. IGUNNE. Facultad de Humanidades. UNNE. Año 12. No 23. Enero - Junio 2015. ISSN 1668-5180 Resistencia, Chaco

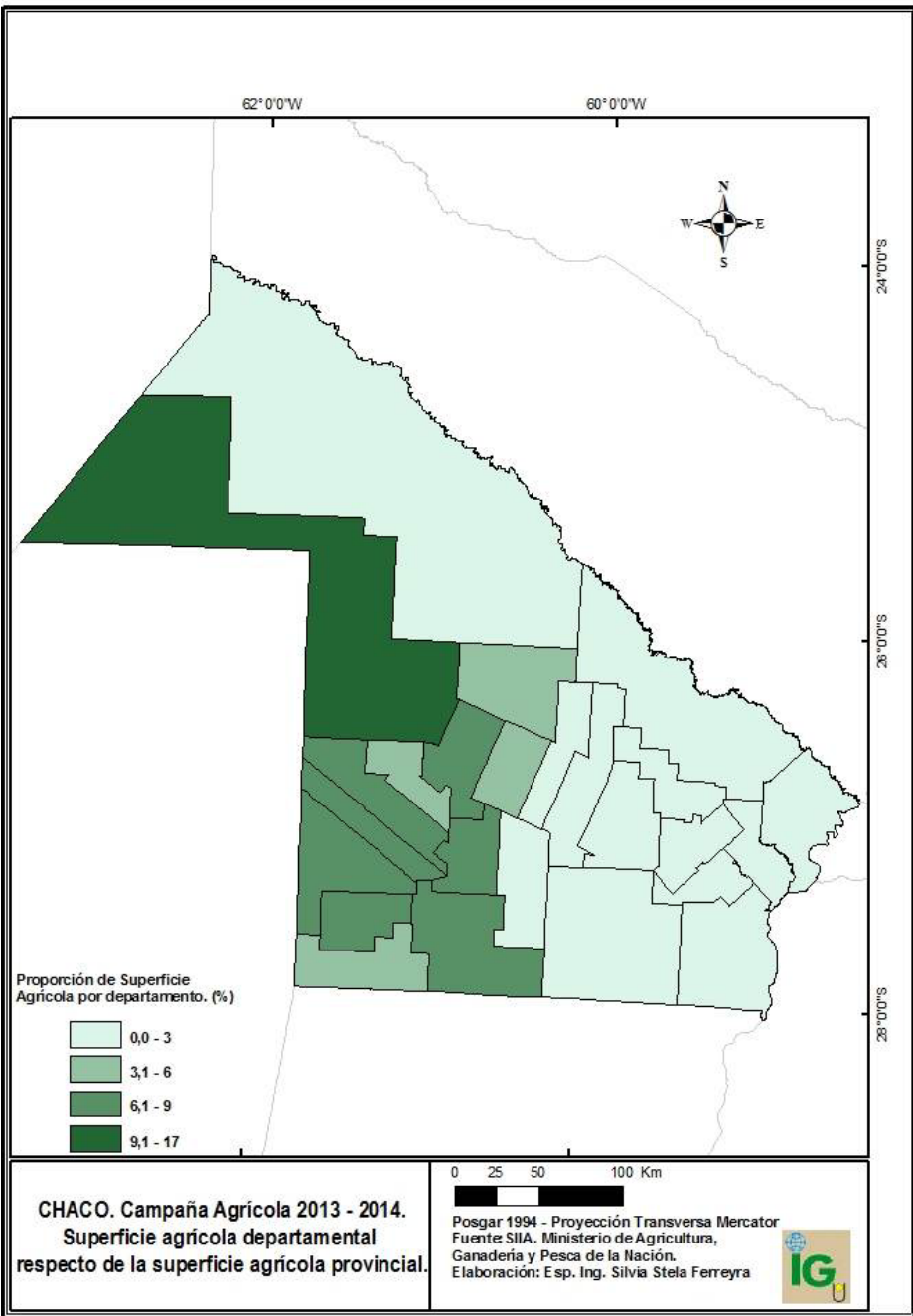

Figura $\mathbf{N}^{\circ} \mathbf{9}$

Desde el punto de vista agrícola, pueden reconocerse cuatro etapas en el Chaco: a) el monocultivo algodonero, entre 1930 y 1960; b) la diversificación agrícola (coexistencia del algodón con otros cultivos), entre 1961 y 1985; c) el resurgimiento algodonero, entre 1986 y 1998 (predominio del algodón sobre otros cultivos); d) la expansión sojera, entre 1999 y el presente (predominio de la soja).

\section{La dinámica ganadera}

"Las zonas abandonadas por la explotación forestal, con su secuela de montes depredados y emigración, encontrarán en la ganadería una actividad económica sustitutiva." (Maeder, E., 1997: 201) Algo semejante ocurrió con las tierras dedicadas al algodón en gran parte del centro y oriente chaqueño, luego de la crisis del textil que se hizo manifiesta a partir de 1960, las cuales quedaron disponibles para el pastoreo.

El gran despegue de la ganadería vacuna extensiva en el Chaco se produjo en la segunda mitad de la década de 1980, superándose los dos millones de cabezas en los años '90. Entre 1995 y 2011 , se observa que la provincia acrecentó sus existencias bovinas en un 34\%. Las sequías de 2008 y, sobre

Publicado en formato digital: Dr. Dante Edin Cuadra y otros. CAMBIOS EN LAS ACTIVIDADES AGROPECUARIAS Y FORESTALES DE LA PROVINCIA DEL CHACO (ARGENTINA) Y SUS EFECTOS SOBRE LA POBLACIÓN RURAL. Revista Geográfica Digital. IGUNNE. Facultad de Humanidades. UNNE. Año 12. No 23. Enero - Junio 2015. ISSN 1668-5180 Resistencia, Chaco.

En: http://hum.unne.edu.ar/revistas/geoweb/default.htm 
todo de 2009, afectó la producción debido a la mortandad que originó en amplias extensiones de la provincia, obligando a vender a muy bajos precios los terneros e, incluso, las madres para aliviar la carga de los campos gravemente afectados por la contingencia meteorológica (Figura $\mathrm{N}^{0} 10$ ). Es destacable que entre los departamentos que experimentaron un aumento por encima del $100 \%$, se hallan General Güemes y Almirante Brown, en el noroeste provincial, lo que pone en evidencia que la frontera ganadera en los últimos años avanza hacia el llamado Impenetrable. También es notoria la expansión ganadera en departamentos que en décadas anteriores tenían sus tierras dedicadas mayoritariamente a la agricultura, como Maipú, 9 de Julio, O`Higgins y Sargento Cabral, que aumentaron sus stocks de vacunos entre un 58 y $68 \%$ en el mismo período, en parte gracias al desmonte.

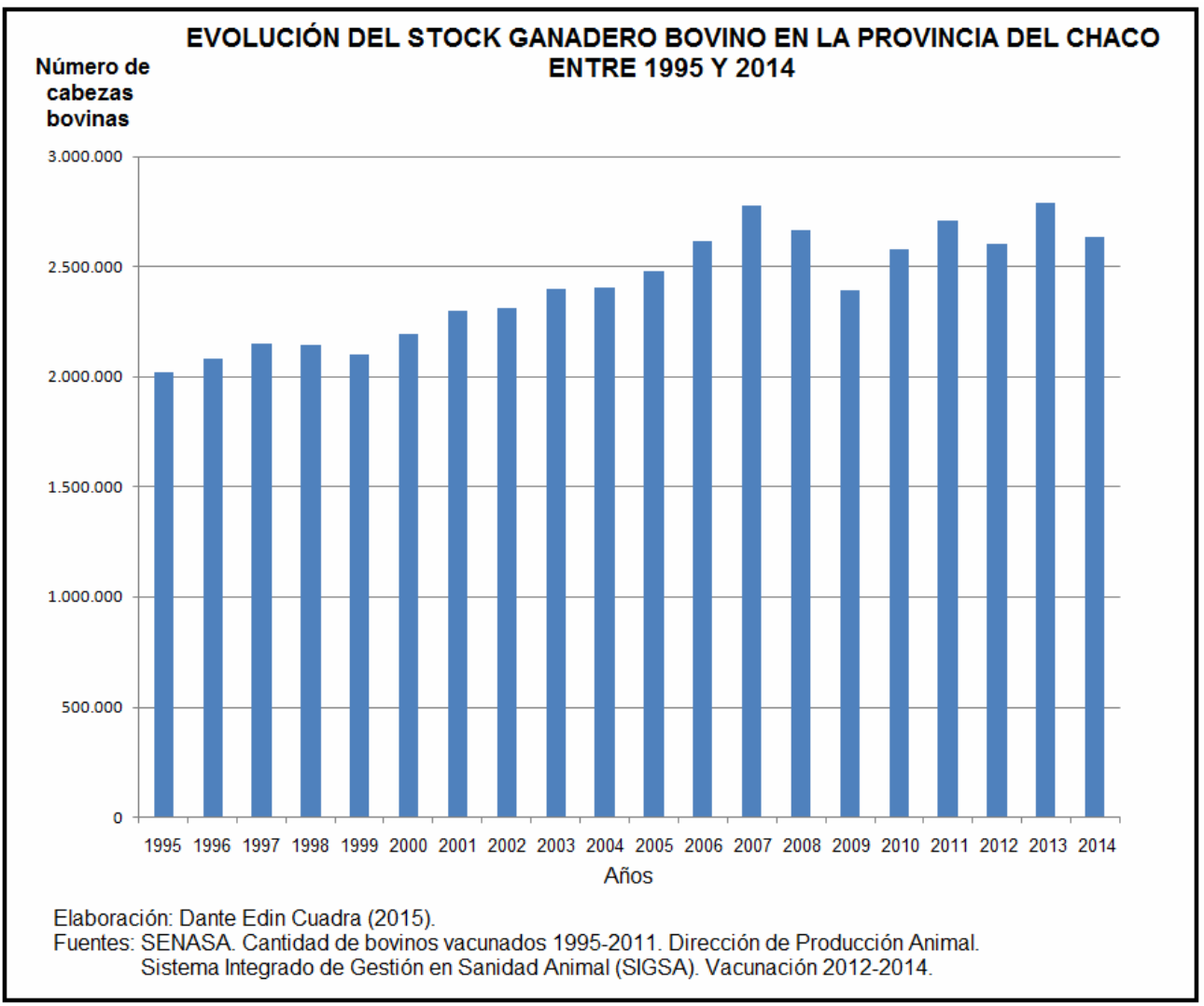

Figura $N^{\circ} 10$

Un mapa publicado por el SENASA (Servicio Nacional de Sanidad y Calidad Agroalimentaria), referido a la variación de las existencias bovinas entre 2008 y 2010 a nivel departamental para la totalidad de la República Argentina, muestra claramente que los dos departamentos noroccidentales del Chaco, han sido los que experimentaron -en términos absolutos- el mayor aumento a nivel nacional.

Publicado en formato digital: Dr. Dante Edin Cuadra y otros. CAMBIOS EN LAS ACTIVIDADES AGROPECUARIAS Y FORESTALES DE LA PROVINCIA DEL CHACO (ARGENTINA) Y SUS EFECTOS SOBRE LA POBLACIÓN RURAL. Revista Geográfica Digital. IGUNNE. Facultad de Humanidades. UNNE. Año 12. No 23. Enero - Junio 2015. ISSN 1668-5180 Resistencia, Chaco.

En: http://hum.unne.edu.ar/revistas/geoweb/default.htm 


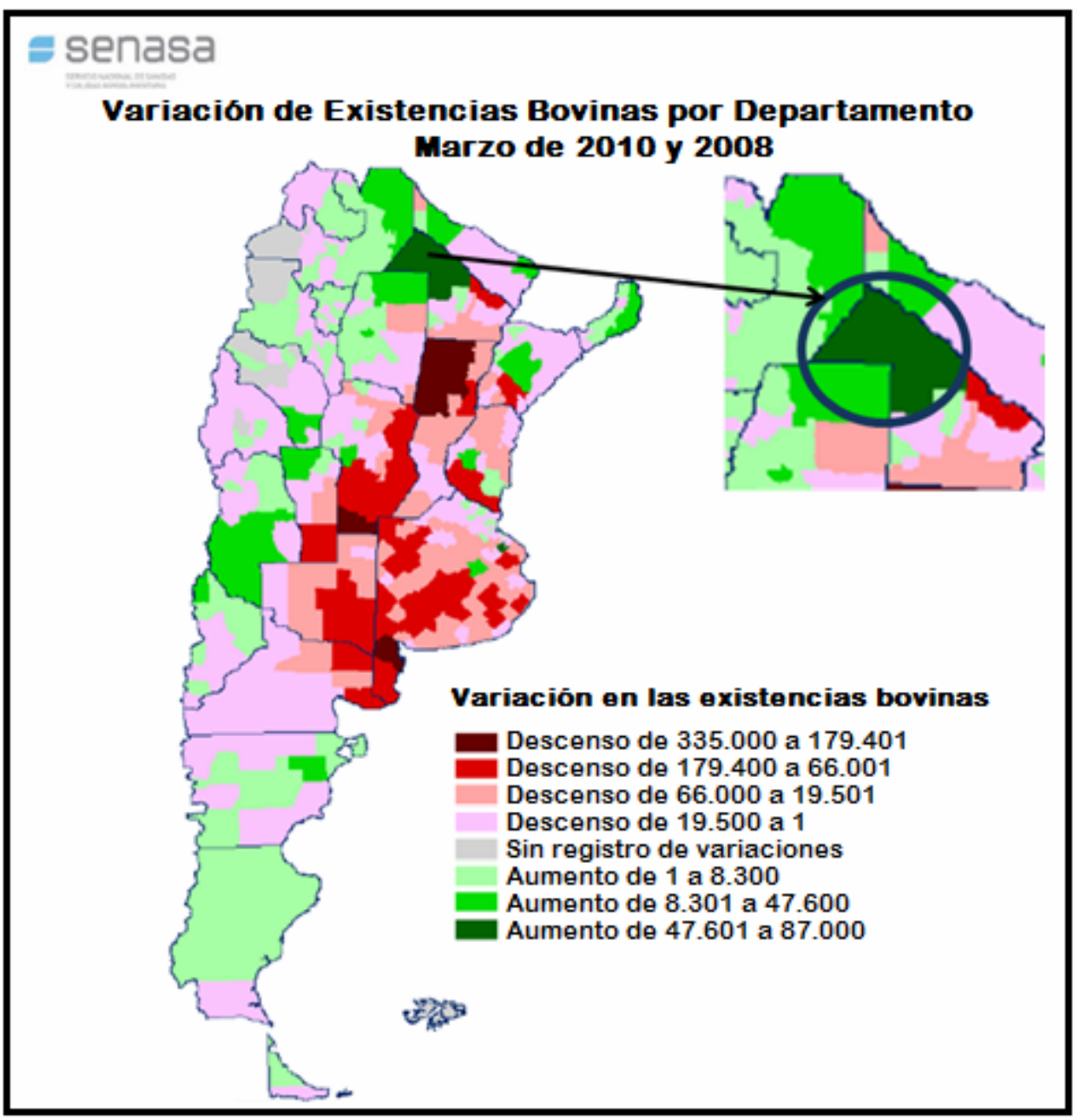

Figura $N^{\circ} 11$

Para reforzar lo enunciado anteriormente, se han analizado los datos de existencias bovinas en la provincia entre los años 1995 y 2011 (datos de SENASA y Dirección de Producción Animal del Ministerio de Producción del Chaco), donde se evidencia que en el término de 16 años, el aumento registrado en los departamentos noroccidentales de Almirante Brown fue de $144 \%$ y de General Güemes $113 \%$, al tiempo que en Chacabuco (ubicado en el sudoeste, con escasa ganadería inicialmente) el incremento fue de $171 \%$. Contrariamente, fueron varias las jurisdicciones agrícolas del centro-sudoeste que redujeron sus planteles ganaderos, tales como Independencia (-96\%), 12 de Octubre (-17\%) y Mayor Luis Fontana (-11\%). Entre los departamentos que ampliaron sus existencias bovinas encontramos a Maipú (68\%), Sargento Cabral (64\%), O`Higgins (62\%), 9 de Julio (58\%), Tapenagá (50\%), Presidencia de la Plaza y Bermejo (45\%). Es evidente que aquéllas áreas donde aumentaron tanto la ganadería como la agricultura, han tenido como variable de ajuste innegablemente- a los bosques nativos, tales los casos de Almirante Brown y Maipú en el noroeste, 9 de Julio y, en menor medida O`Higgins, en el sudoeste. Ello no significa que en las otras jurisdicciones donde la agricultura y/o la ganadería experimentaron reducciones no hayan existido importantes extracciones forestales, situación que se observa en General Güemes, Libertador General San Martín

Publicado en formato digital: Dr. Dante Edin Cuadra y otros. CAMBIOS EN LAS ACTIVIDADES AGROPECUARIAS Y FORESTALES DE LA PROVINCIA DEL CHACO (ARGENTINA) Y SUS EFECTOS SOBRE LA POBLACIÓN RURAL. Revista Geográfica Digital. IGUNNE. Facultad de Humanidades. UNNE. Año 12. No 23. Enero - Junio 2015. ISSN 1668-5180 Resistencia, Chaco.

En: http://hum.unne.edu.ar/revistas/geoweb/default.htm 
e Independencia (este último departamento, prácticamente se deshizo de la ganadería, convirtiendo sus tierras pecuarias y forestales en áreas de cultivos).

El aumento del número de cabezas ha sido moderado en la mitad oriental de la provincia, en general por debajo del $50 \%$, espacio en el que la ganadería se ha ido consolidando desde hace varias décadas hasta constituirse en la actividad predominante, incorporando tierras forestales y áreas que fueron anteriormente agrícolas, sobre todo algodoneras.

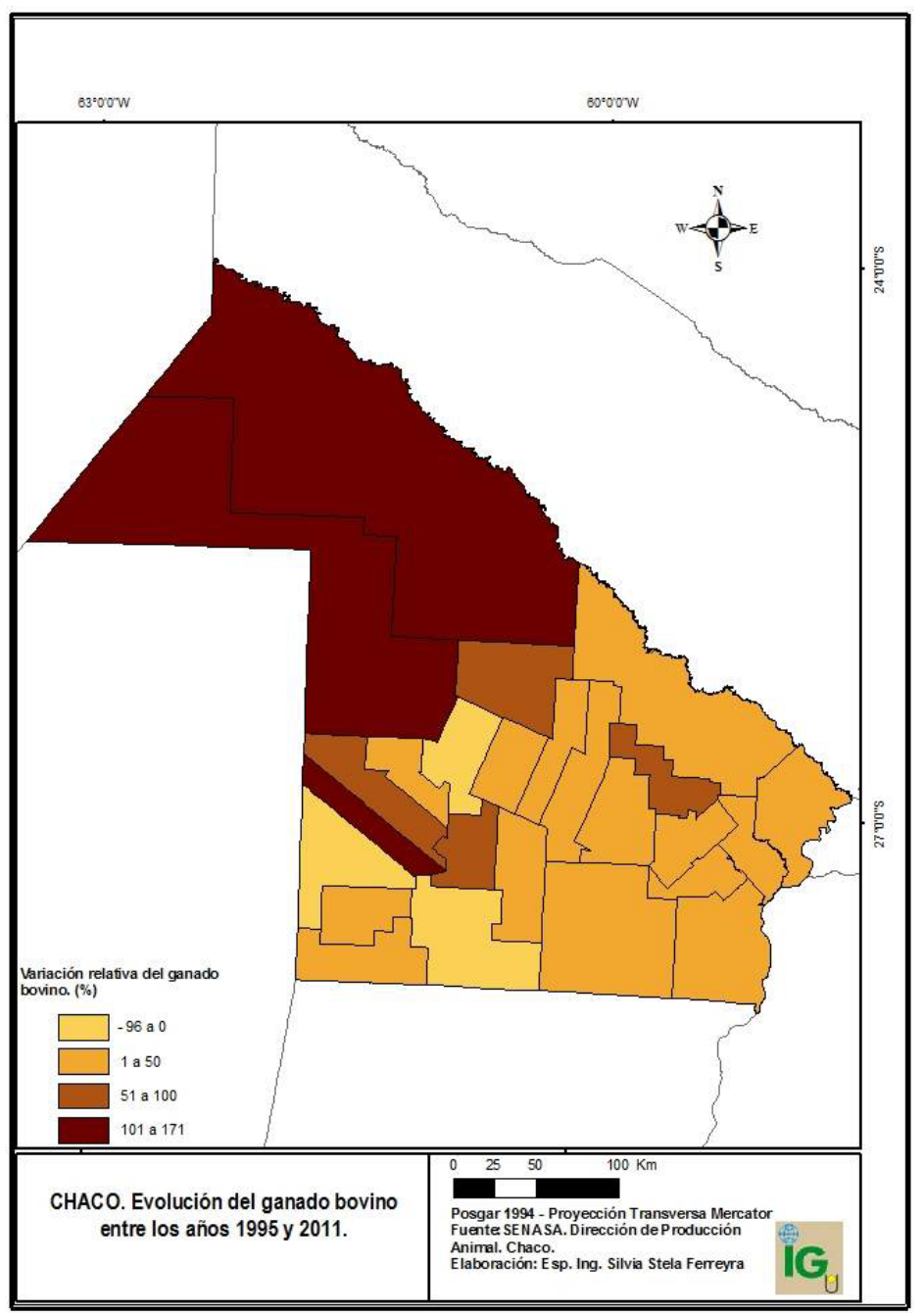

Figura $N^{\circ} 12$

El stock ganadero bovino del Chaco era de 1,5 millones al promediar la década de 1980 y, actualmente, oscila entre 2,6 y algo más de 2,7 millones de cabezas (años 2012 a 2014), es decir que el incremento ocurrido en casi tres décadas ha sido del 56\%. La distribución del ganado vacuno en la provincia muestra, en términos relativos, que ningún departamento contiene más del $15 \%$ de las existencias totales. Nuevamente aparecen con mayor gravitación los departamentos General Güemes y Almirante Brown, a los que se les suman Libertador General San Martín en el noreste y Tapenagá en el sur de la provincia. Algunas jurisdicciones del sur, centro y este exponen proporciones que

Publicado en formato digital: Dr. Dante Edin Cuadra y otros. CAMBIOS EN LAS ACTIVIDADES AGROPECUARIAS Y FORESTALES DE LA PROVINCIA DEL CHACO (ARGENTINA) Y SUS EFECTOS SOBRE LA POBLACIÓN RURAL. Revista Geográfica Digital. IGUNNE. Facultad de Humanidades. UNNE. Año 12. No 23. Enero - Junio 2015. ISSN 1668-5180 Resistencia, Chaco.

En: http://hum.unne.edu.ar/revistas/geoweb/default.htm 
oscilan entre 5 y $7 \%$ del total provincial, tales los casos de Bermejo, San Fernando, 25 de Mayo y Mayor Luis Fontana.

Los departamentos netamente agrícolas del centro-sudoeste (sojeros), junto con dos jurisdicciones con escasa actividad económica primaria, como $1^{\circ}$ de Mayo y Libertad (situados en el este), se caracterizan por sostener proporciones exiguas de vacunos, con valores que varían entre 0 y $2 \%$ del total provincial.

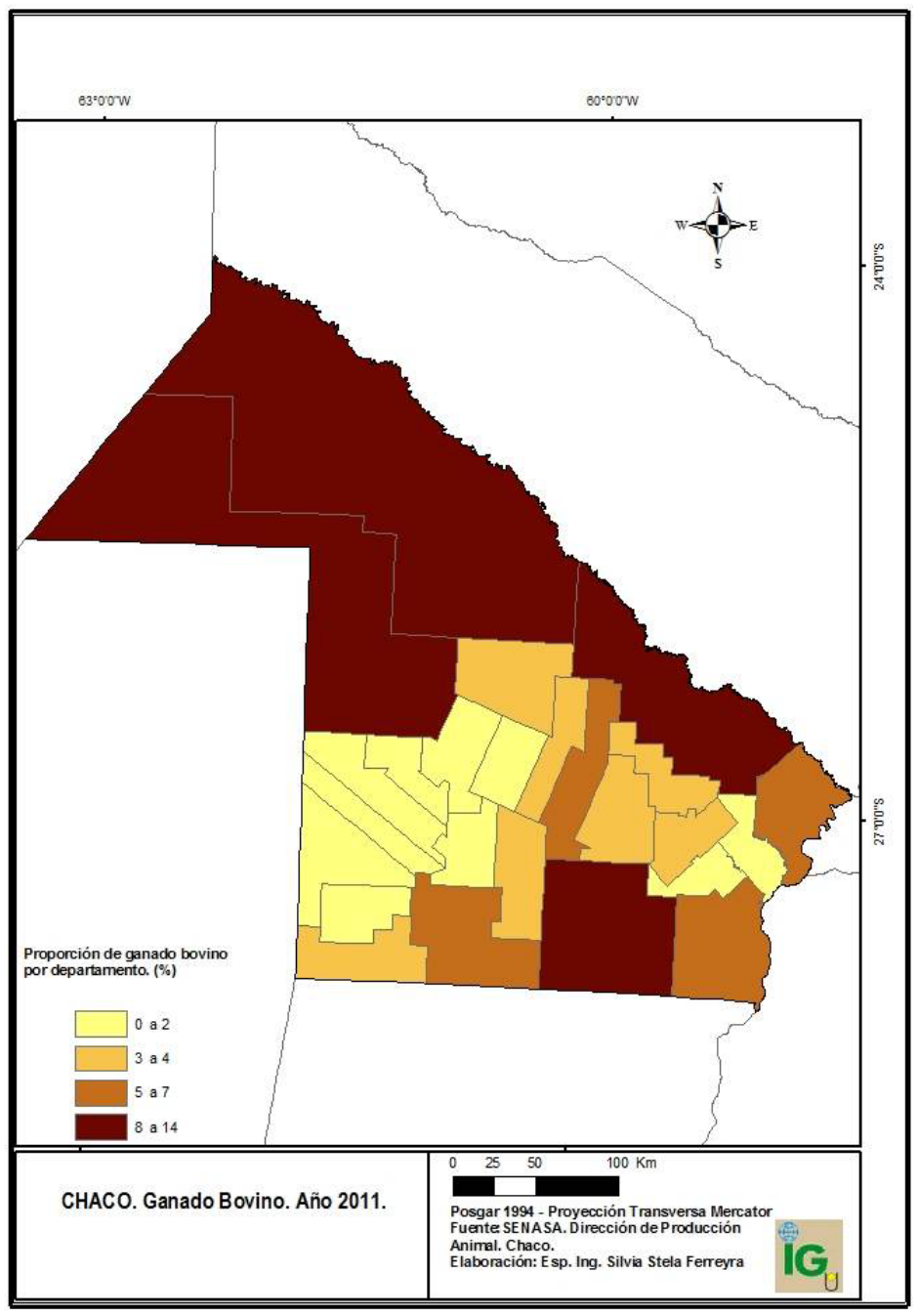

Figura $N^{\circ} 13$

La explicación de por qué los departamentos del noroeste provincial, teniendo la mayor cantidad de cabezas vacunas son los que más aumentan sus existencias, queda respondida al observar el mapa de densidad ganadera bovina (Figura $\mathrm{N}^{\circ} 14$ ). Allí se advierte que, justamente por la gran superficie de estas jurisdicciones forestales, son las menos recargadas a nivel pecuario $y$, por tanto, admiten en su interior la incorporación de un número mayor de animales. Por el contrario, el sector sudoeste -que también evidencia baja densidad ganadera-, tiene la mayor parte de sus tierras destinadas a usos agrícolas, por lo que las posibilidades de introducir ganado se hacen más dificultosas.

Publicado en formato digital: Dr. Dante Edin Cuadra y otros. CAMBIOS EN LAS ACTIVIDADES AGROPECUARIAS Y FORESTALES DE LA PROVINCIA DEL CHACO (ARGENTINA) Y SUS EFECTOS SOBRE LA POBLACIÓN RURAL. Revista Geográfica Digital. IGUNNE. Facultad de Humanidades. UNNE. Año 12. No 23. Enero - Junio 2015. ISSN 1668-5180 Resistencia, Chaco.

En: http://hum.unne.edu.ar/revistas/geoweb/default.htm 
La mitad oriental del Chaco muestra las mayores densidades bovinas, sobre todo los departamentos Bermejo, General Dónovan, Sargento Cabral, 25 de Mayo y Mayor Luis Fontana. Entre el área Noroccidental de menores densidades ( 1 a 18 cabezas por $\mathrm{km}^{2}$ ) y la franja centro-oriental de mayores densidades (36 a 57 cabezas $/ \mathrm{km}^{2}$ ), se aprecia un grupo de departamentos que muestran densidades intermedias, a modo de área de transición conformada por Maipú, Comandante Fernández, O`Higgins, General Belgrano, Chacabuco y Fray Justo Santa María de Oro (19 a 35 cabezas $/ \mathrm{km}^{2}$ ).

Ante este escenario caracterizado por la existencia de un espacio ganadero emplazado en la mitad oriental de la provincia y del núcleo agrícola implantado en el centro-sudoeste, se evidencia en consecuencia, que el único espacio con potencialidad para expandir e intensificar la actividad ganadera bovina en el Chaco (al menos con el patrón productivo tradicional) se localiza en el noroeste, situación que -justamente- se viene registrando en los últimos años.

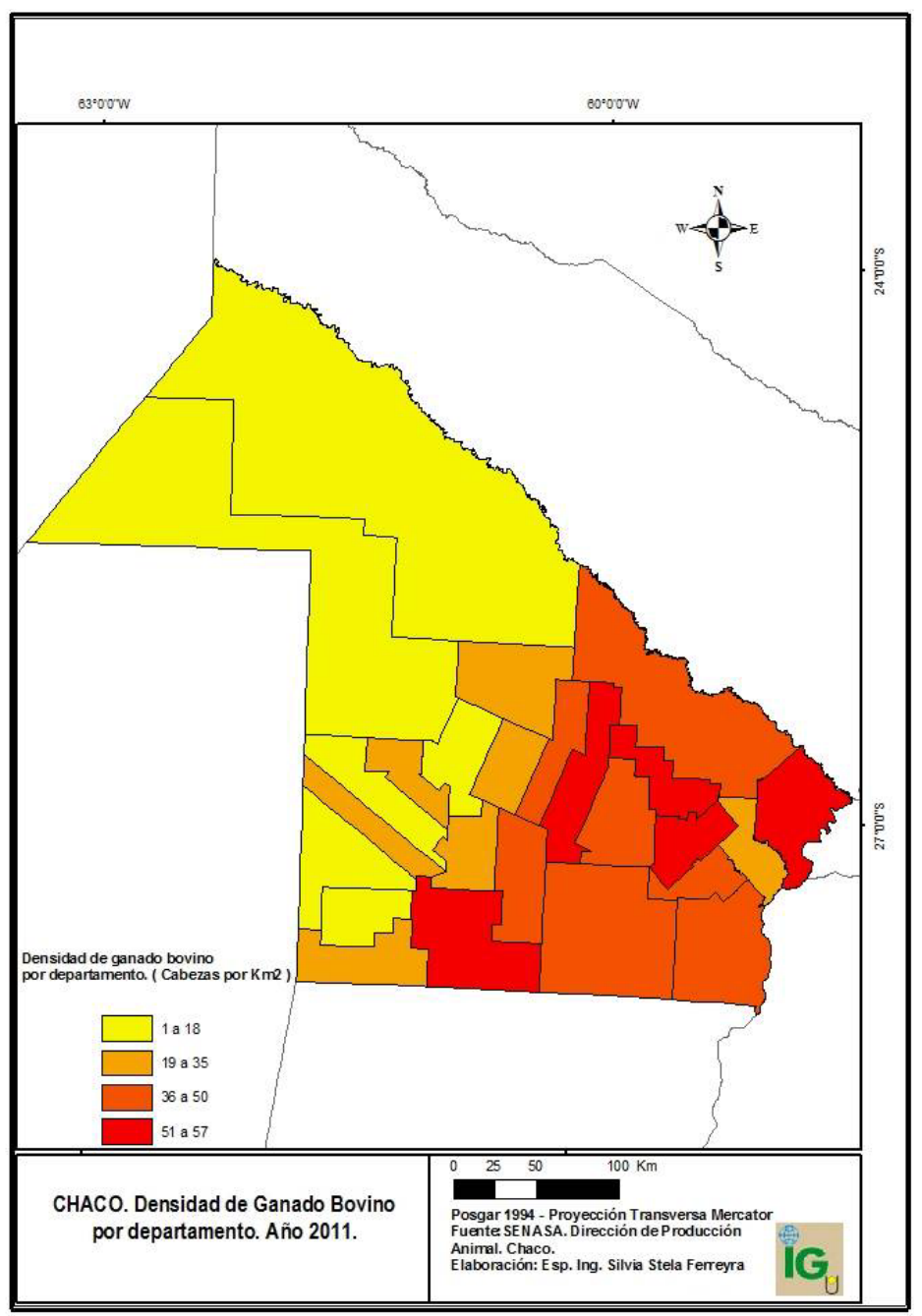

Figura $N^{\circ} 14$

Publicado en formato digital: Dr. Dante Edin Cuadra y otros. CAMBIOS EN LAS ACTIVIDADES AGROPECUARIAS Y FORESTALES DE LA PROVINCIA DEL CHACO (ARGENTINA) Y SUS EFECTOS SOBRE LA POBLACIÓN RURAL. Revista Geográfica Digital. IGUNNE. Facultad de Humanidades. UNNE. Año 12. No 23. Enero - Junio 2015. ISSN 1668-5180 Resistencia, Chaco.

En: http://hum.unne.edu.ar/revistas/geoweb/default.htm 
Revista Geográfica Digital. IGUNNE. Facultad de Humanidades. UNNE. Año 12. No 23. Enero - Junio 2015. ISSN 1668-5180 Resistencia, Chaco

\section{La dinámica forestal}

La explotación maderera se ha mantenido alta en los últimos años, a pesar de la sanción de la nueva ley nacional de bosques № 26.331 (de "Presupuestos mínimos de protección ambiental para el enriquecimiento, la restauración, conservación, aprovechamiento y manejo sostenible de los bosques nativos"), que fue sancionada y promulgada a fines del año 2007 y reglamentada en febrero de 2009 a través del decreto $N^{0}$ 91/09. El Chaco, en sintonía con dicha normativa, dio cumplimiento a tal requerimiento mediante la sanción de la ley provincial № 6.409 del año 2009 , el decreto reglamentario $\mathrm{N}^{\circ} 932$ del año siguiente y su modificatorio № 81/11.

Entre la década de 1940 y fines de los años '70, la extracción forestal en el Chaco se movió por arriba y por debajo de las 800.000 toneladas anuales. De allí hasta mediados de los ' 80 la actividad declinó fuertemente hasta registrar un piso inferior a las 300.000 toneladas. Pero en los años siguientes se inició una escalada sin precedentes que la llevó a superar el millón de toneladas en la segunda mitad de la década de 1990 e, incluso, a sobrepasar el valor de 1,3 millones entre los años 2004 y 2006. Este severo impulso de la explotación forestal experimentó una desaceleración durante el proceso de sanción y promulgación de la ley nacional de bosques № 26.331 desde 2007 hasta su reglamentación en 2009, año en que la provincia del Chaco sancionó su propia ley de bosques, para reglamentarla a principios de 2010.

Se observa claramente que la atenuación en la intensidad de la explotación forestal en la provincia, no logró mantenerse una vez habilitadas las correspondientes normativas, exhibiendo desde entonces valores anuales siempre por arriba de la línea del millón de toneladas, aunque inferiores a los años que precedieron a la aprobación, promulgación y reglamentación de la ley nacional de bosques. En consecuencia, el efecto del cambio normativo ha sido de leve impacto, lo que no significa garantía de sustentabilidad en las prácticas que se llevan a cabo sobre el bosque nativo chaqueño, dado que los montos continúan siendo elevados y, máxime, si se toma en cuenta la extracción efectuada en términos históricos. El promedio de explotación anual entre 2010 y 2012 ha sido de 1.151 .084 toneladas, equivalente a 3.154 toneladas diarias, sin considerar las extracciones ilegales.

Maderas extraídas de los bosques nativos de la Provincia del Chaco

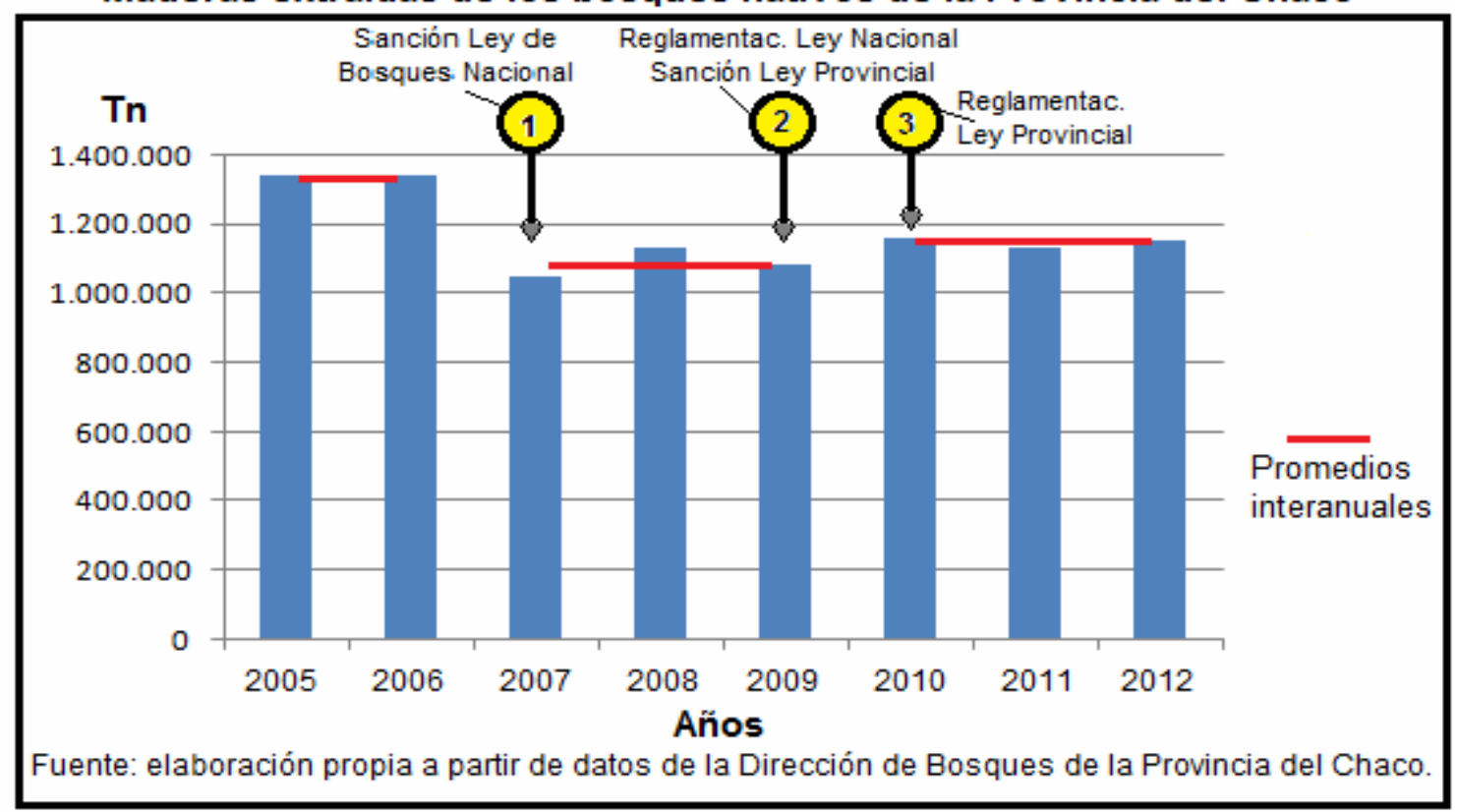

Publicado en formato digital: Dr. Dante Edin Cuadra y otros. CAMBIOS EN LAS ACTIVIDADES AGROPECUARIAS Y FORESTALES DE LA PROVINCIA DEL CHACO (ARGENTINA) Y SUS EFECTOS SOBRE LA POBLACIÓN RURAL. Revista Geográfica Digital. IGUNNE. Facultad de Humanidades. UNNE. Año 12. No 23. Enero - Junio 2015. ISSN 1668-5180 Resistencia, Chaco.

En: http://hum.unne.edu.ar/revistas/geoweb/default.htm 


\section{Figura $\mathbf{N}^{\circ} 15$}

Entre 2001 y 2013, el volumen de maderas extraídas de los bosques nativos en la provincia del Chaco, superior al millón de toneladas anuales, mostró un crecimiento de 7,4\%. En el año 2001, la mayor actividad forestal se daba en el departamento noroccidental de Almirante Brown, que proveía un tercio $(32,5 \%)$ del total de maderas producidas en la provincia. Cinco jurisdicciones, la mayoría limítrofes a ese departamento, aportaban también sus recursos maderables (entre 5 y 10\% cada una), tales los casos de Maipú, General Güemes, Libertador General San Martín y 9 de Julio. De los seis departamentos nombrados se extraía el $70 \%$ de las riquezas maderables obtenidas en la provincia. Una decena de departamentos del centro, centro-este y centro-oeste proveían individualmente entre 1 y $5 \%$ de las demandas, en tanto, el área sur y este (a la que se sumaba Quitilipi, en el centro) no llegaba a contribuir con el 1\% por jurisdicción, respecto de la producción total provincial. Debe recordarse que esta franja meridional y oriental sufrió una intensa explotación durante la primera mitad del siglo XX por parte de las empresas productoras de tanino.

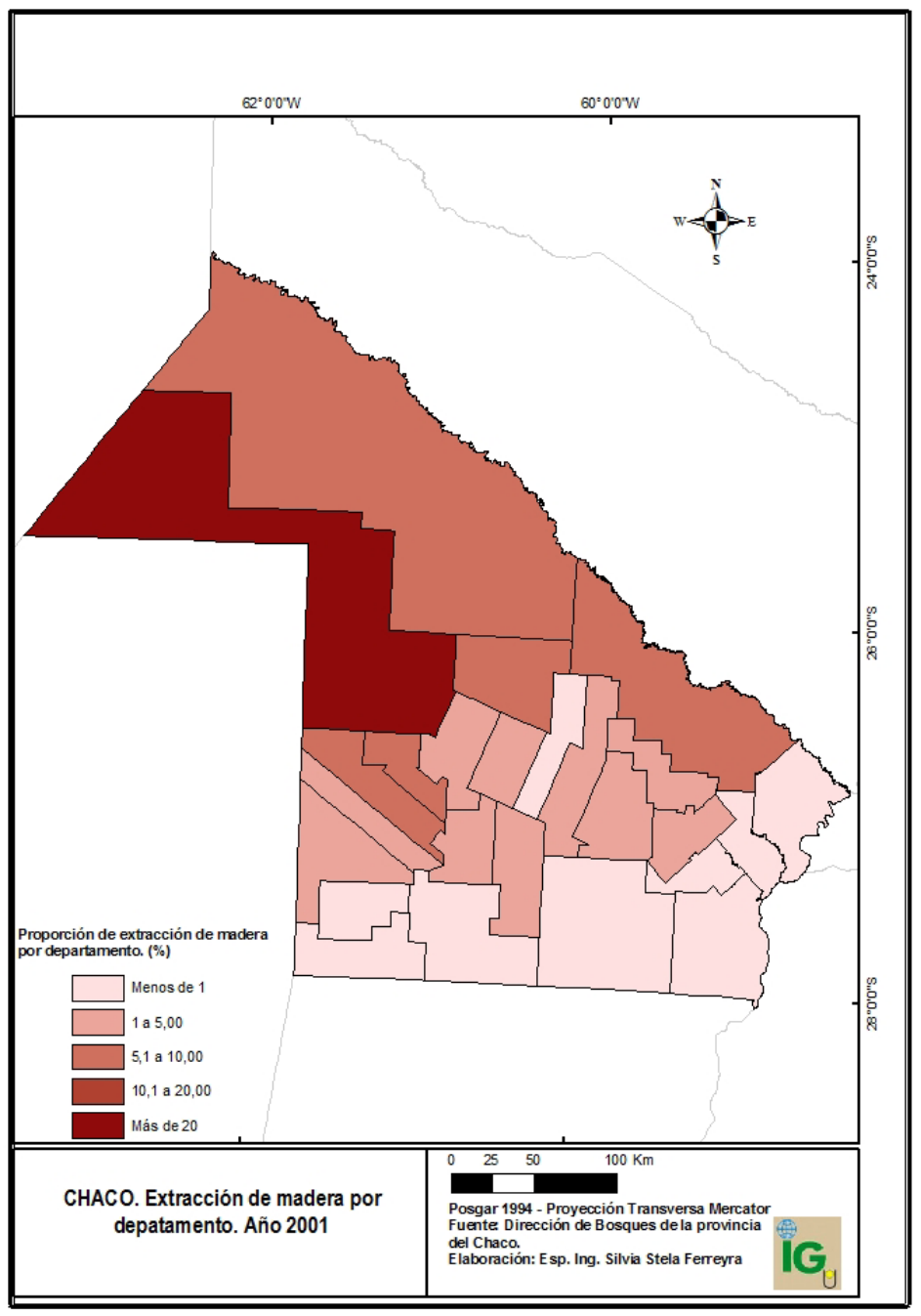

Figura No 16

Publicado en formato digital: Dr. Dante Edin Cuadra y otros. CAMBIOS EN LAS ACTIVIDADES AGROPECUARIAS Y FORESTALES DE LA PROVINCIA DEL CHACO (ARGENTINA) Y SUS EFECTOS SOBRE LA POBLACIÓN RURAL. Revista Geográfica Digital. IGUNNE. Facultad de Humanidades. UNNE. Año 12. No 23. Enero - Junio 2015. ISSN 1668-5180 Resistencia, Chaco.

En: http://hum.unne.edu.ar/revistas/geoweb/default.htm 
En el año 2013 la situación no varió demasiado en cuanto a las áreas proveedoras, respecto de 2001. Pero sí aumentó fuertemente la presión ejercida sobre los bosques nativos del noroeste provincial: Almirante Brown pasó a aportar el $41,3 \%$ de los recursos madereros demandados en el Chaco, en tanto General Güemes lo hacía con 15,1\%, Maipú con 8,4\%, 9 de Julio con 5,7\% y Libertador General San Martín con 5,1\%. Ello implica que de los bosques nativos de estos cinco departamentos se extrae la $3 / 4$ parte $(76 \%)$ de la madera utilizada en el Chaco (al menos, teniendo en cuenta las estadísticas oficiales). Diez departamentos del centro, centro-este, centro-oeste y sur de la provincia hacen aportes menores, al tiempo que los del extremo sudoeste, sudeste, este y noreste (acompañados por Quitilipi y Presidencia de la Plaza, en el centro) intervienen con valores muy acotados.

Gran parte de la producción maderera tiene como destino las industrias tanineras ubicadas en La Escondida y Puerto Tirol (que demandan quebracho colorado y leña) y las fábricas de muebles, aberturas, postes y artículos rurales que se localizan en Machagai, Quitilipi, Presidencia de la Plaza, General San Martín, Juan José Castelli, Tres Isletas y otros puntos de la provincia. El $64 \%$ de las maderas se destinan a leña, el $18,4 \%$ a rollos, el $16,5 \%$ a rollizos y el $1,1 \%$ a postes.

\section{Figura $N^{\circ} 17$}

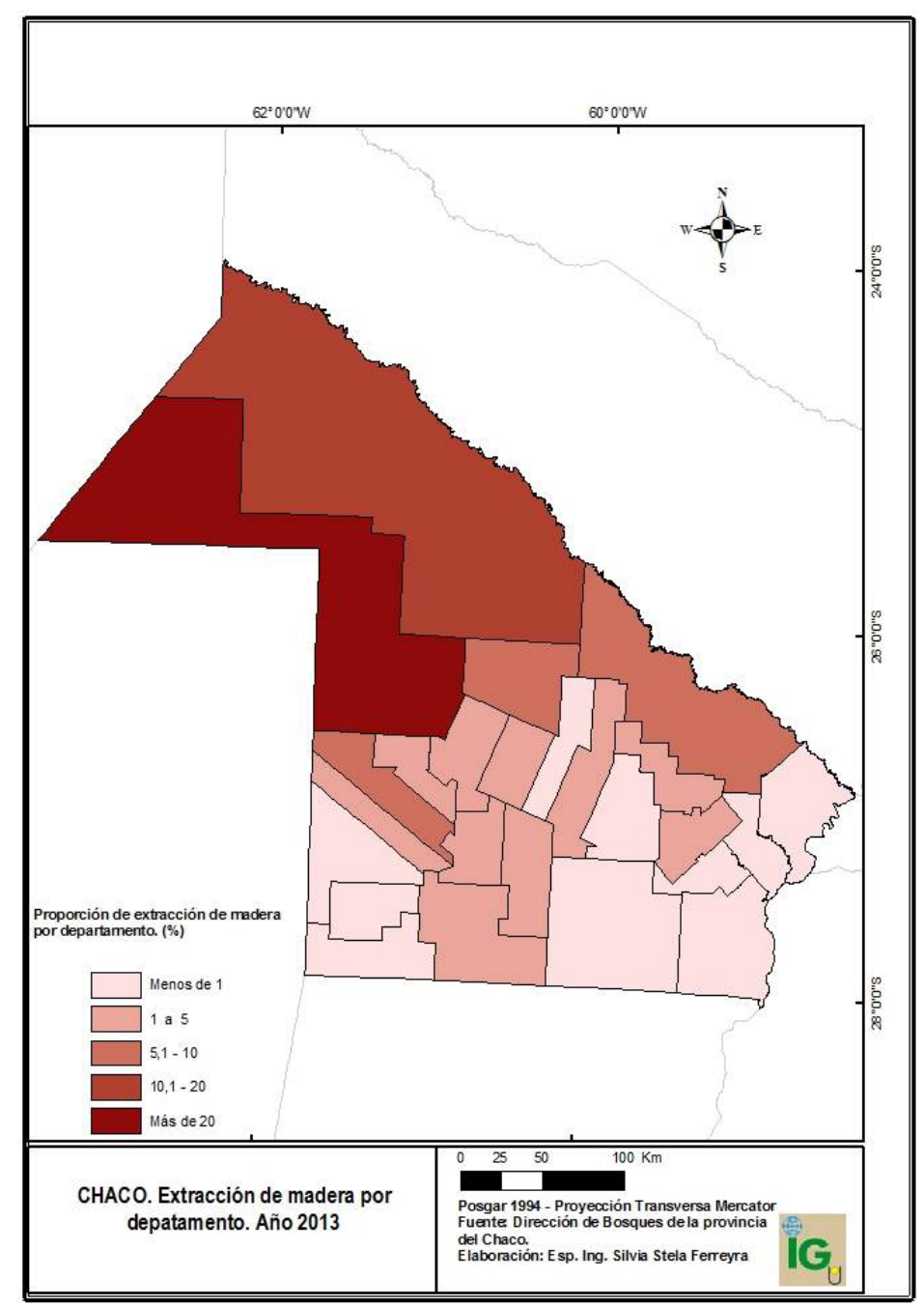

Publicado en formato digital: Dr. Dante Edin Cuadra y otros. CAMBIOS EN LAS ACTIVIDADES AGROPECUARIAS Y FORESTALES DE LA PROVINCIA DEL CHACO (ARGENTINA) Y SUS EFECTOS SOBRE LA POBLACIÓN RURAL. Revista Geográfica Digital. IGUNNE. Facultad de Humanidades. UNNE. Año 12. No 23. Enero - Junio 2015. ISSN 1668-5180 Resistencia, Chaco.

En: http://hum.unne.edu.ar/revistas/geoweb/default.htm 
Revista Geográfica Digital. IGUNNE. Facultad de Humanidades. UNNE. Año 12. No 23. Enero - Junio 2015. ISSN 1668-5180 Resistencia, Chaco

\section{La dinámica demográfica}

La población rural en el Chaco viene mostrando una tendencia fuertemente decreciente desde 1960 hasta el presente. En el período comprendido entre mediados de la década de 1980 y el año 2010 la pérdida fue de un $36 \% \mathrm{y}$, para este último año, sólo tenían residencia en el medio rural 162.571 habitantes (sumando la población agrupada y dispersa), equivalente a 15,4\% de la población total de la provincia.

En el Chaco, los tres departamentos norteños presentan montos importantes de población rural: General Güemes (25.809 habitantes), Libertador General San Martín (17.618 habitantes) y Bermejo (11.315 habitantes). Los dos primeros tienen grandes extensiones y, no obstante la predominancia de las actividades ganaderas y forestales existentes allí, también disponen de tierras dedicadas a la agricultura. Bermejo, de menor superficie, contiene un área pecuaria con accesibilidad a numerosos centros urbanos próximos (Las Palmas, La Leonesa, General Vedia, Puerto Bermejo, Puerto Eva Perón e Isla del Cerrito) y, además, ha incorporado la actividad agrícola arrocera en los últimos años, aunque su desarrollo es todavía incipiente.

Otras jurisdicciones del noroeste (Almirante Brown y Maipú), del centro (Comandante Fernández, Quitilipi y 25 de Mayo), del sudoeste (9 de Julio y Mayor Luis Fontana) y del este (Sargento Cabral y San Fernando), aún sostienen una población rural dentro del rango de 5.000 a 10.000 habitantes rurales. En los restantes departamentos, el monto de población residente en el campo es inferior a 5.000 habitantes. (INDEC, 2010)

Entre los años 2001 y 2010, la población rural dispersa, que -en términos generales- es la que desarrolla efectivamente actividades agropecuarias y forestales, tuvo un importante desgranamiento en toda la provincia, a excepción del departamento Bermejo, en su extremo noreste, que mostró un comportamiento de crecimiento leve (entre 0 y $2 \%$ ), que estaría dado por algunas mejoras a nivel de la producción ganadera intensiva, la accesibilidad a las áreas rurales y el emplazamiento de la actividad arrocera. Los departamentos General Güemes y Maipú (en el noroeste de la provincia), 25 de Mayo (en el centro), O`Higgins y Fray Justo Santa María de Oro (en el sudoeste) experimentaron una pérdida superior al 9\%. Esta expresión espacial de la emigración rural refleja claramente que ninguna de las actividades económicas primarias desarrolladas en el Chaco es capaz de retener a la población residente en el campo, dado que General Güemes es un departamento ganadero-forestal, Maipú es Agrícola-forestal (con predominio del cultivo de soja), 25 de Mayo es ganadero y, los dos restantes, están orientados a la agricultura (algodón y soja).

Una disminución significativa, entre 6 y $9 \%$, se dio en el centro y sur de la provincia donde predomina la actividad ganadera (Presidencia de la Plaza, Quitilipi, San Lorenzo y Tapenagá), pero también en el área sojera del sudoeste (General Belgrano, 9 de Julio y 2 de Abril). Una pérdida más moderada, entre 3 y $6 \%$, se produjo en varias jurisdicciones ubicadas en diferentes lugares de la provincia, como ha ocurrido en Almirante Brown, Independencia y Comandante Fernández (centro-noroeste), Chacabuco y Mayor Luis Fontana (sudoeste), Libertador General San Martín, General Dónovan y $1^{\circ}$ de Mayo (noreste), también con actividades diferenciadas entre las áreas. Una reducción leve, inferior al $3 \%$, se observa en los departamentos Sargento Cabral, Libertad y San Fernando, otrora algodoneros (situados en el sector oriental ganadero del Chaco), a los que se suma 12 de Octubre (ubicado en el núcleo sojero del sudoeste).

Publicado en formato digital: Dr. Dante Edin Cuadra y otros. CAMBIOS EN LAS ACTIVIDADES AGROPECUARIAS Y FORESTALES DE LA PROVINCIA DEL CHACO (ARGENTINA) Y SUS EFECTOS SOBRE LA POBLACIÓN RURAL. Revista Geográfica Digital. IGUNNE. Facultad de Humanidades. UNNE. Año 12. No 23. Enero - Junio 2015. ISSN 1668-5180 Resistencia, Chaco.

En: http://hum.unne.edu.ar/revistas/geoweb/default.htm 
Revista Geográfica Digital. IGUNNE. Facultad de Humanidades. UNNE. Año 12. № 23. Enero - Junio 2015. ISSN 1668-5180 Resistencia, Chaco

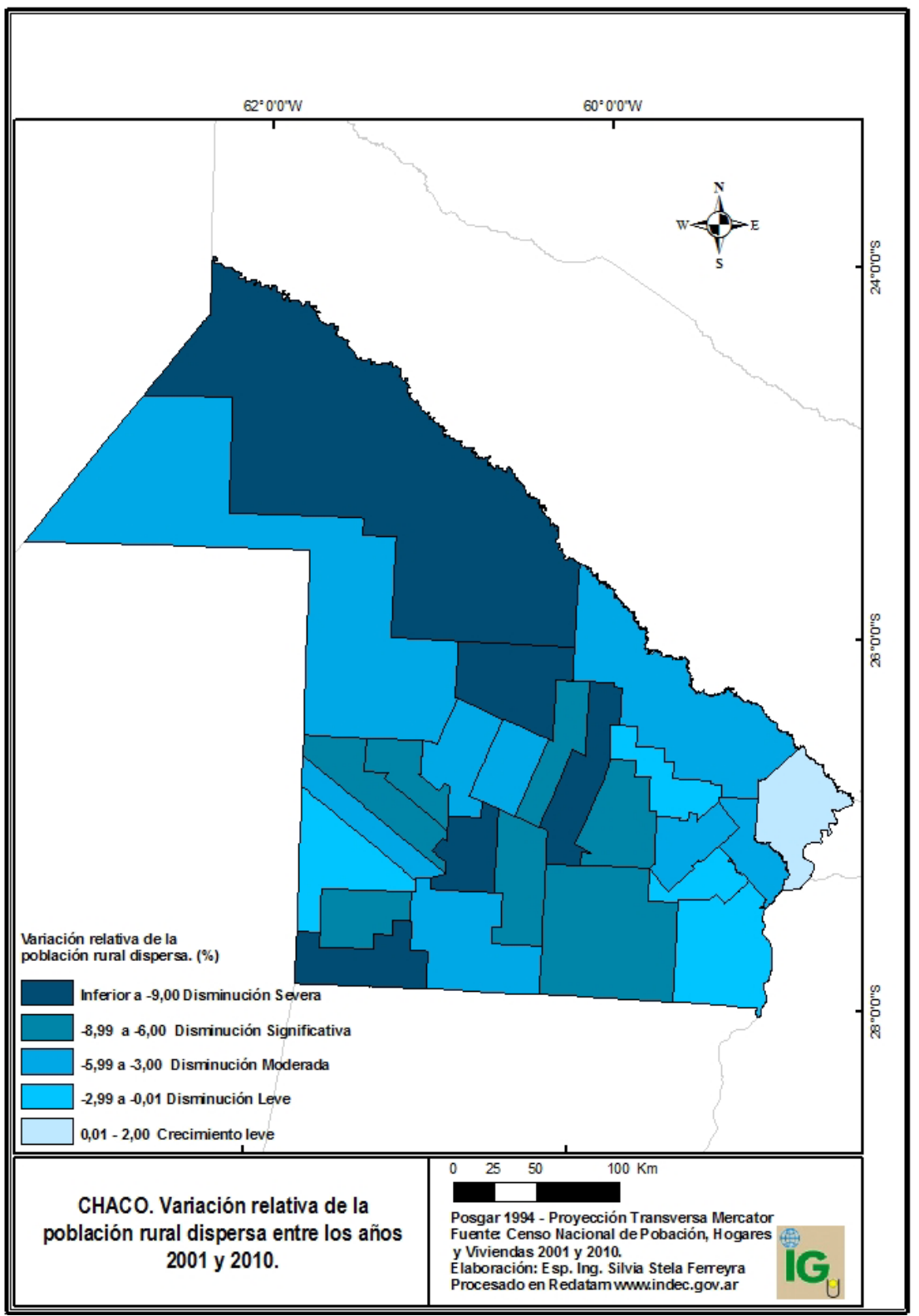

Figura $N^{\circ} 18$

\section{Conclusiones}

El Chaco ha ido cambiando su perfil productivo en distintos momentos de su devenir histórico: inicialmente tuvo un perfil foresto-industrial (hasta 1930), luego algodonero (hasta 1960), más tarde diversificó su economía (coexistencia del algodón con otros cultivos, más la ganadería y la explotación forestal, hasta 1985). Pero resultan sumamente significativos los cambios operados a partir de mediados de la década de 1980 hasta nuestros días, etapa en la que se marca una tendencia de crecimiento de la superficie cultivada, de las existencias bovinas y del aprovechamiento de los

Publicado en formato digital: Dr. Dante Edin Cuadra y otros. CAMBIOS EN LAS ACTIVIDADES AGROPECUARIAS Y FORESTALES DE LA PROVINCIA DEL CHACO (ARGENTINA) Y SUS EFECTOS SOBRE LA POBLACIÓN RURAL. Revista Geográfica Digital. IGUNNE. Facultad de Humanidades. UNNE. Año 12. No 23. Enero - Junio 2015. ISSN 1668-5180 Resistencia, Chaco.

En: http://hum.unne.edu.ar/revistas/geoweb/default.htm 
recursos forestales. Asimismo, a fines de los '90, se ha producido una expansión sin precedentes del cultivo de la soja, quitándole la supremacía que había recuperado el algodón en años anteriores. Estos cambios en las modalidades y escalas de producción de las tres principales actividades económicas primarias ha redistribuido la propia organización del espacio chaqueño, conformándose una nueva regionalización a nivel de las áreas productivas, con fuerte impacto sobre la población rural y el ambiente. De este modo, pueden reconocerse claramente cuatro unidades geográficas en la provincia: a) Área con perfil ganadero (en el centro, sureste y este); b) Área netamente agrícola en el centro y sudoeste; c) Área agrícola-forestal en el centro, oeste y noroeste; d) Área ganadera-forestal en el norte y noroeste.

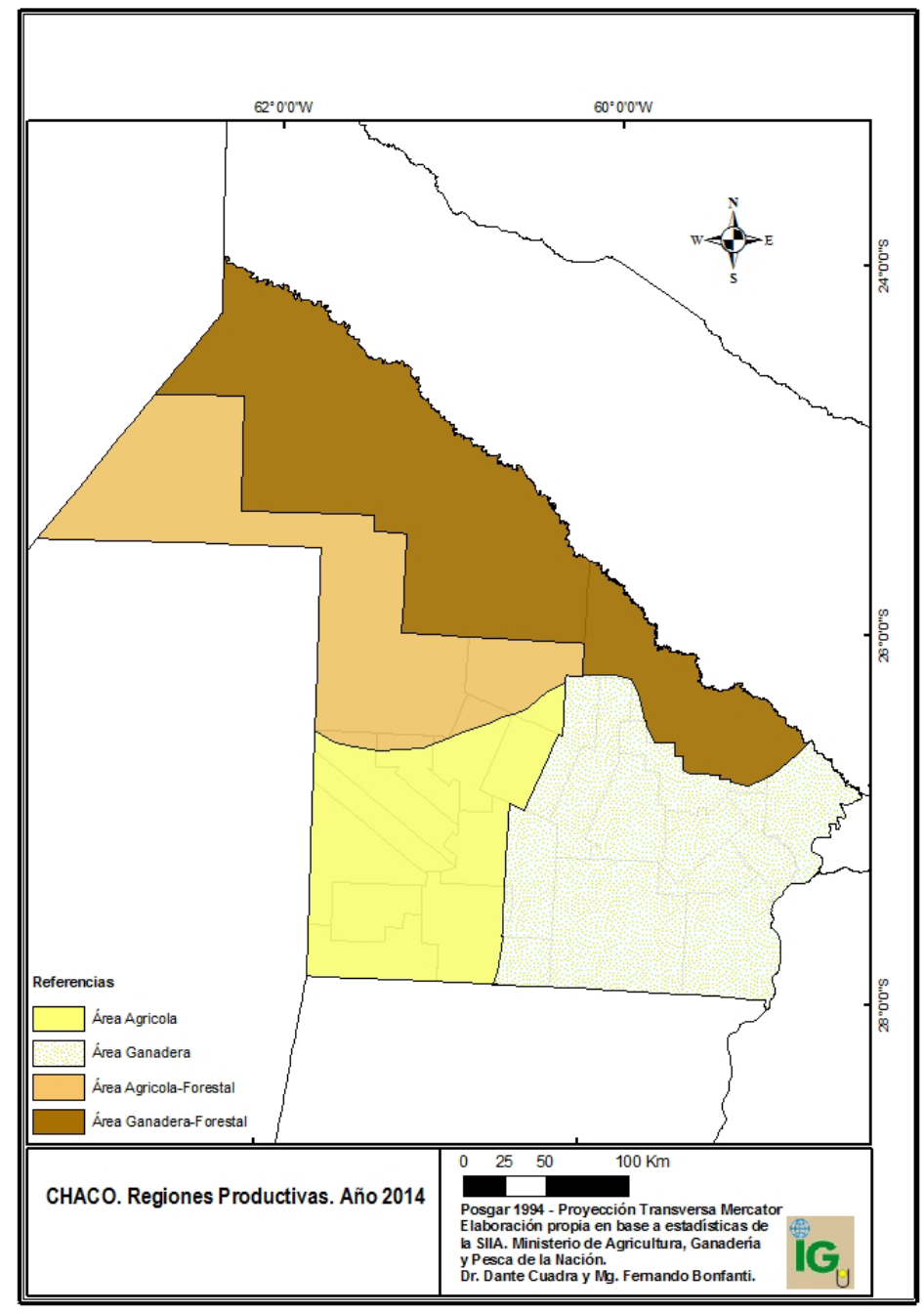

Figura $N^{\circ} 19$

Todas las actividades impulsadas, a diferencia del pasado ciclo algodonero, tienen por común denominador la escasa generación de empleo rural y el establecimiento de condiciones económicas y ambientales que no alientan, ni favorecen la permanencia de los actuales habitantes en ese medio. Tanto la ganadería, como la agricultura mecanizada y la extracción forestal tienden a manejarse con

Publicado en formato digital: Dr. Dante Edin Cuadra y otros. CAMBIOS EN LAS ACTIVIDADES AGROPECUARIAS Y FORESTALES DE LA PROVINCIA DEL CHACO (ARGENTINA) Y SUS EFECTOS SOBRE LA POBLACIÓN RURAL. Revista Geográfica Digital. IGUNNE. Facultad de Humanidades. UNNE. Año 12. No 23. Enero - Junio 2015. ISSN 1668-5180 Resistencia, Chaco.

En: http://hum.unne.edu.ar/revistas/geoweb/default.htm 
Revista Geográfica Digital. IGUNNE. Facultad de Humanidades. UNNE. Año 12. No 23. Enero - Junio 2015. ISSN 1668-5180 Resistencia, Chaco

un personal mínimo portador de saberes muy específicos, cuya residencia o la de sus familias se localizan en el ámbito urbano. Las maderas provenientes de los bosques nativos se procesan en parques industriales radicados en pueblos y ciudades, la cosecha manual ha desaparecido del campo chaqueño y las estancias funcionan con pocos operarios.

El aumento de la superficie agrícola y pecuaria en el Chaco se ha venido produciendo a expensas de las tierras forestales $y$, actualmente, nos encontramos dentro de un proceso de avance ganadero y agrícola en el noroeste provincial, justamente de donde sale el $70 \%$ de las maderas obtenidas en la provincia. La soja y otros cultivos como el girasol, maíz, sorgo y trigo se han expandido sobre áreas anteriormente algodoneras, pero también han ocupado tierras deforestadas. En el centro y este del Chaco, tradicionalmente algodonero, esta actividad prácticamente desapareció del mismo modo que se desmantelaron las principales especies maderables, lo que motivó el fortalecimiento de la ganadería extensiva en el espacio donde se registran las mayores precipitaciones (1.000 a $1.4000 \mathrm{~mm}$ anuales), que bien podría destinarse a cultivos bajo otros patrones de producción.

Este panorama ha dejado en total vulnerabilidad no sólo a la población rural (que bajo el modelo productivo imperante continuará haciendo abandono de los campos y de su cultura laboral, sufriendo la experiencia traumática del desarraigo en los medios urbanos), sino también a las reservas boscosas que se hallan, sobre todo, en el noroeste de la provincia, donde -como se ha visto- los niveles de extracción son significativos, a pesar de los avances producidos en materia de protección legal de los bosques nativos en años recientes.

Finalmente, la dinámica y configuración geográfica que se ha pretendido mostrar aquí, de hecho simplificada por el número acotado de variables analizadas, pone de manifiesto que en materia de organización territorial el Chaco tiene grandes desafíos por delante. Este estado de situación reclama la necesaria planificación de estrategias capaces de garantizar la sustentabilidad de las actividades económicas y de los distintos ambientes involucrados y, para ello, es fundamental no perder de vista un aspecto que en la etapa posmoderna que transitamos a menudo se olvida, como es el compromiso de organizar (recrear, ordenar) los espacios geográficos sin afectar la justicia social.

\section{Bibliografía y materiales consultados}

BARBEITO, A. y LO VUOLO, R. (1995): La Modernización Excluyente. Transformación Económica y Estado de Bienestar en Argentina. Buenos Aires, Losada S.A.

BESIL, Antonio C. (1969): Análisis de las causas del actual cambio en la estructura del sector agrícola de la provincia del Chaco. Tesis Doctoral. Facultad de Ciencias Económicas, UNNE. Resistencia, Argentina.

BRUNIARD Enrique D. (1992): El ámbito subtropical en la República Argentina (Climatología dinámica y límites climáticos). En: Estudios Geográficos $N^{\circ} 208$, Revista publicada por el Instituto de Economía y Geografía Aplicadas, Madrid, España.

BRUNIARD, Enrique D. (1979): El Gran Chaco Argentino. Revista Geográfica No 4. Instituto de Geografía. UNNE. Resistencia, Argentina.

BRUNIARD, Enrique D.(1981): El Clima de las planicies del norte argentino (Tesis Doctoral). Facultad de Humanidades UNNE. Resistencia, Argentina.

BÜNSTORF, Jürgen (1982): El papel de la industria taninera y de la economía agropecuaria en la ocupación del espacio chaqueño. Folia Histórica del Nordeste № 5 . Resistencia-Corrientes, Argentina. Instituto de Historia -Facultad de Humanidades - UNNE e Instituto de Investigaciones Geohistóricas - CONICET. Pp. 7 a 59.

Publicado en formato digital: Dr. Dante Edin Cuadra y otros. CAMBIOS EN LAS ACTIVIDADES AGROPECUARIAS Y FORESTALES DE LA PROVINCIA DEL CHACO (ARGENTINA) Y SUS EFECTOS SOBRE LA POBLACIÓN RURAL. Revista Geográfica Digital. IGUNNE. Facultad de Humanidades. UNNE. Año 12. No 23. Enero - Junio 2015. ISSN 1668-5180 Resistencia, Chaco.

En: http://hum.unne.edu.ar/revistas/geoweb/default.htm 
BURGOS, Juan J. (1970): El clima de la Región Nordeste de la República Argentina en relación con la vegetación natural y el suelo. En: Boletín de la Sociedad Argentina de Botánica, Volumen XI, Buenos Aires, Argentina.

Cámara de Diputados de la Nación Argentina (2009): Ley No 26.331 de Presupuestos Mínimos de Protección Ambiental de los Bosques Nativos. Buenos Aires, Argentina.

CUADRA, Dante E. (2012): Problemática forestal en la Provincia del Chaco, Argentina. Un análisis desde la Geografía. Revista Geográfica Digital. Año 9. № 18. Julio - Diciembre 2012. Resistencia, Chaco. IGUNNE. Facultad de Humanidades. UNNE. En: http://hum.unne.edu.ar/revistas/geoweb/default.htm

DIRECCIÓN DE BOSQUES DE LA PROVINCIA DEL CHACO (2009): Ley Provincial No 6409. En línea: http://cedei.produccion.chaco.gov.ar/Bosques/Forestal\%20N/DECRETO\%20\%202596-09.pdf

FUNDACION PARA LA EDUCACION, LA CIENCIA Y LA CULTURA, (1988): El Deterioro del Ambiente en la Argentina (Suelo-agua-Vegetación-Fauna). Buenos Aires, Argentina.

GORI, Gastón (1974): La Forestal: la tragedia del quebracho colorado. Resistencia, Argentina. Proyección.

ICAC RECORDER (1997): Información Técnica y Estadística del cultivo del Algodón. En formato Digital (CD-Room).

INDEC. (2001/2010). Censos de Población y Vivienda. Buenos Aires, Argentina.

INSAURRALDE, Juan Ariel (2014): La reducción de los bosques nativos durante la última expansión agrícola. El caso del Suroeste chaqueño. Provincia del Chaco, Argentina (1990 - 2010). Universidad Nacional del Nordeste (UNNE) - Universidad Nacional del Sur (UNS) - Consejo Nacional de Investigaciones Científico Tecnológicas (CONICET). http://observatoriogeograficoamericalatina.org.mx/egal14/Procesosambientales/Impactoambiental/34.p df

INTA - EERA de Presidencia Roque Sáenz Peña: Mapa de Capacidad de Uso del Suelo en el Chaco. Escala 1:500.000.

INTA (Instituto Nacional de Tecnología Agropecuaria) (1965): Guías prácticas agrometeorológicas. Publicación Miscelánea № 34, Buenos Aires, Argentina.

KUGLER, Nicolás D. (1994): Razones para migrar. Una estudio de población del Chaco Algodonero. Tesis de Licenciatura (Inédito). UBA. Buenos Aires, Argentina.

MAEDER, Ernesto J. (1997): Historia del Chaco. Colección: Historia de nuestras provincias. Buenos Aires, Argentina. Ed. Plus Ultra.

MANOILOFF, Raúl O. (2001): El cultivo del algodón en el Chaco entre 1950 y nuestros días: la etapa de crisis. Resistencia, Argentina: Meana Editores.

MANOILOFF, Raúl O. (2005): La crisis del algodón en el Chaco y los cultivos alternativos. Corrientes, Argentina: Moglia S.R.L.

MANOILOFF, Raúl y otros (2007, 2008, 2009 y 2011): Atlas Geográfico de la Provincia del Chaco. Tomos: I, II, III y IV. Revista Geográfica No 14, 15, 16 y 17. Resistencia, Argentina. Instituto de Geografía de la UNNE.

MINISTERIO DE LA PRODUCCIÓN DE LA PROVINCIA DEL CHACO. Secretaría de Recursos Naturales Dirección de Bosques: Estadísticas. Años 2001-2012. P.R.S. Peña, Argentina.

Publicado en formato digital: Dr. Dante Edin Cuadra y otros. CAMBIOS EN LAS ACTIVIDADES AGROPECUARIAS Y FORESTALES DE LA PROVINCIA DEL CHACO (ARGENTINA) Y SUS EFECTOS SOBRE LA POBLACIÓN RURAL. Revista Geográfica Digital. IGUNNE. Facultad de Humanidades. UNNE. Año 12. N No 23. Enero - Junio 2015. ISSN 1668-5180 Resistencia, Chaco.

En: http://hum.unne.edu.ar/revistas/geoweb/default.htm 
Revista Geográfica Digital. IGUNNE. Facultad de Humanidades. UNNE. Año 12. No 23. Enero - Junio 2015. ISSN 1668-5180 Resistencia, Chaco

MINISTERIO DE LA PRODUCCIÓN DE LA PROVINCIA DEL CHACO (2013): Sistema de Geo Estadísticas. Resistencia, Argentina.

MIRANDA, Guido (1955): Tres Ciclos Chaqueños. Crónica histórica regional. Resistencia, Argentina. Ed. Norte Argentino.

PELLERANO, Liliana L; ROSELLO BRAJOVICH, José Emilio y BALBUENA, Osvaldo (2003): Análisis económico de modelos ganaderos de cría bovina Este de Chaco. INTA. Colonia Benítez, Chaco. En línea: http://inta.gob.ar/documentos/analisis-economico-de-modelos-ganaderos-de-criabovina-este-de-chaco/

PEPE, Norberto C. y DEREWICKI, José V. (1997): Su majestad el Algodón. Resistencia, Argentina. Ed. Meana y Meana.

PERTILE, Viviana C. (2004): Ampliación de la Frontera Agropecuaria Chaqueña: El Oeste chaqueño y el cultivo algodonero. En: Revista Geográfica Digital. Instituto de Geografía (IGUNNE) Facultad de Humanidades. UNNE. Año 1. No 1. Marzo - Abril. ISSN 1668-5180. Resistencia, Argentina. http://hum.unne.edu.ar/revistas/geoweb/homeig0.htm

PERTILE, Viviana C. y TORRE GERALDI, Alejandra H. (2011): El Oeste chaqueño. Una aproximación a la relación hombre-naturaleza. Revista Geográfica Digital. IGUNNE. Facultad de Humanidades. UNNE. Año 8. № 16. Julio - Diciembre 2011. ISSN 1668-5180 Resistencia, Argentina. En: http://hum.unne.edu.ar/revistas/geoweb/default.htm

RAMIREZ, Mirta L. (1996): Análisis y perspectivas de la situación agroproductiva y social de las provincias del Nordeste Argentino, Paraguay y Estados del Sur de Brasil. Tesis de Licenciatura (Inédito). Facultad de Humanidades. UNNE. Resistencia, Argentina.

ROCCATAGLIATA, J. A. (1988): La Argentina: geografía general y los marcos regionales. Buenos Aires, Argentina. Grupo Editorial Planeta Argentina.

TORRE GERALDI, Alejandra. H. (2004): El cultivo de la soja en el Chaco. Problemática productiva del sector agrícola provincial, en el marco de su inserción en el clúster oleaginoso argentino. Obtenido de http://www.unne.edu.ar/Web/cyt/com2004/1 -Sociales/S-008.pdf

VALEIRO, Alejandro (1998): El Nuevo Algodón ¿Son sustentables los cambios recientes del sector algodonero Argentino?. INTA. Santiago del Estero, Argentina.

VALENZUELA, Cristina (2005): Transformaciones y conflictos en el agro chaqueño durante los '90. Articulaciones territoriales de una nueva racionalidad productiva. Revista Mundo Agrario, v.5 n.10 La Plata ene./jun. 2005. Versión On-line ISSN 1515-5994. La Plata, Argentina.

ZARRILLI, Adrián (2000): Transformaciones ecológicas y precariedad económica en una economía marginal. El gran chaco argentino, 1890-1950. Theomai, primer semestre, $\mathrm{N}^{0} 1$, Universidad Nacional de Quilmes. Quilmes, Argentina. Disponible en: http://revistatheomai.unq.edu.ar/numero1/artzarrilli1.htm

ZARRILLI, Adrián (2008): Bosques vs agricultura. Los límites históricos de sustentabilidad de los bosques argentinos en en contexto de explotación capitalista. (1900-1950). Luna Azul (26): 87-106, ILUS TAB, 2008, Jun.

ZARRILLI, Adrián (2010): ¿Una agriculturización insostenible? La provincia del Chaco, Argentina (1980-2008). Obtenido de http:// http://www.historiaagraria.com

Publicado en formato digital: Dr. Dante Edin Cuadra y otros. CAMBIOS EN LAS ACTIVIDADES AGROPECUARIAS Y FORESTALES DE LA PROVINCIA DEL CHACO (ARGENTINA) Y SUS EFECTOS SOBRE LA POBLACIÓN RURAL. Revista Geográfica Digital. IGUNNE. Facultad de Humanidades. UNNE. Año 12. No 23. Enero - Junio 2015. ISSN 1668-5180 Resistencia, Chaco.

En: http://hum.unne.edu.ar/revistas/geoweb/default.htm 